\title{
Dissecting Trade and Business Cycle Co-movement*
}

\author{
Paul I. $\mathrm{Ko}^{\dagger}$ \\ The Pennsylvania State University
}

October 27, 2020

Click HERE for the latest version

\begin{abstract}
International business cycles have become highly synchronized across countries in the past three decades, yet there is a lack of consensus on whether this is due to an increase in the correlation of countryspecific shocks or due to increased economic integration. To understand this empirical phenomenon, I develop a multi-country real business cycle model with international trade that captures several potential explanations: shocks to productivity, demand, leisure, investment, sectoral expenditures, and tradelinkages. By matching the data exactly with the endogenous outcomes of the model, shocks fully account for the data such as GDP and trade shares. Calibrating the model to a panel of developed (G7) countries during 1992-2014, I find that trade-linkage shocks, which capture the increased economic integration and volatility of trade flows, are essential in synchronizing international business cycles. In contrast, other correlated country-specific shocks play relatively minor roles. This suggests that trade shocks due to economic integration have been the primary driver of the co-movement of international business cycles. Furthermore, I use my model to address the trade co-movement puzzle, which states that international real business cycle models should be predicting a much stronger link between trade and cross-country GDP correlations. Once I account for the trade-linkage shocks, the model predicts a strong link between trade and business cycle co-movement. This finding suggests that incorporating the dynamics of trade shocks is crucial when studying international business cycles.
\end{abstract}

Keywords: International business cycles; Business cycle synchronization; International trade; Business cycle accounting

JEL Classifications: E32, E37, F15, F41, F44, F62

${ }^{*}$ I am indebted to my advisors Jonathan Eaton and Kim Ruhl for their invaluable guidance, continuous support and mentorship throughout this project. I am grateful to Stephen Yeaple, Ruilin Zhou, Jingting Fan, David Argente, Elisa Giannone and Neil Wallace for helpful comments. I received helpful feedback from Ji-Woong Moon, Gee Young Oh, Nathan Converse, Armela Mancellari, Nestor Azcona, François de Soyres, Karthik Nagarajan, and Jamie Kim. I also want to thank seminar participants at Midwest Macro (Univ. of Georgia), CIREQ Ph.D. Students' Conference (McGill), Midwest Trade (Indiana Univ.), EEA-ESEM (Manchester), WEAI, YES, and Pre-Job Market Conference at the Federal Reserve Board for fruitful discussions. I am grateful for Chung-Han Yang for sharing his organized WIOT data.

${ }^{\dagger}$ Department of Economics, The Pennsylvania State University, e-mail: pik106@psu.edu 


\section{Introduction}

As the world's economies have become more globalized, international business cycles have become more synchronized. On the one hand, with the growth of international trade, countries have become economically integrated as they face trade shocks, which, in turn, synchronize their business cycles across trading partners. On the other hand, an increase in correlated country-specific shocks, such as productivity or demand, has affected the increase in international business cycle synchronization. Understanding the process and the specific drivers of international business cycle synchronization is necessary for fully anticipating the effects of country- or region-specific policies on another and on the broader global economy. However, there is still a lack of consensus on what is generating cross-country business cycle synchronization. Since both country-specific, correlated shocks and shocks through international trade linkages affect business cycles in each country, we need a comprehensive account of global business cycle co-movement that addresses all of these forces in a holistic way.

In this paper, I ask two fundamental questions: (1) What are the main drivers of the co-movement of international business cycles? (2) Does international trade play a crucial role in creating such an empirical phenomenon? To answer these questions, I construct a multi-country international real business cycle model with various shocks. The embedded shocks allow the model to be fully saturated so that it replicates the data exactly. By identifying shocks that are accountable for the movements in various macroeconomic aggregates, I give a full account of international business cycles. I find that the trade-linkage shocks, which capture the growth and volatility of bilateral trade flows, are primarily responsible for synchronizing international business cycles, while other country-specific, correlated shocks play relatively minor roles.

Disentangling the various forces that influence cross-country business cycle synchronization is not an easy task, since these forces affect business cycles simultaneously. Productivity shocks are one of the common potential explanations for business cycle synchronization; as productivity shocks are more positively correlated across countries, output across countries will be more synchronized. However, a standard international real business cycle model that only allows for productivity shocks cannot generate the cross-country co-movement that we observe from the data (Backus et al. (1992)). Another potential explanation is that correlated demand shocks, where each country's increased consumption generates higher outputs, lead to the positive business cycle co-movement. Correlated labor shocks, too, are a potential explanation, as an increased correlation in employment can lead to the output correlation. Furthermore, investment-driven shocks may be the answer, as they create higher correlations to the returns to capital in each country, which, in turn, drive the output co-movement. Shocks to the composition of economic sectors may be important also, as many developed countries have experienced a gradual shift from manufacturing to services in the composition of their economies.

In addition to the country-specific correlated shocks, the world has experienced a considerable increase in international trade as countries have become more economically integrated. ${ }^{1}$ There has been much evidence that country-pairs that trade more with each other have a higher degree of business cycle synchronization. As the global trade-to-GDP ratio increased from $40 \%$ in the early 1990 s to $60 \%$ in the 2010 s, countries have experienced growth in trade, while domestic shares of countries' expenditure have decreased significantly across the world. Therefore, disentangling these forces involves assimilating these economic shocks to

\footnotetext{
${ }^{1}$ There are other forms of integration such as financial markets and foreign direct investments (FDIs). In this paper, I focus on the economic integration that results from trade.
} 
understand their contributions to global business cycle synchronization.

To dissect the effects of various shocks on global business cycle synchronization, I build a two-sector multi-country international real business cycle (IRBC) model with input-output linkages and saturate the model with shocks to (i) productivities in producing merchandised goods and (ii) services, (iii) aggregate demand, (iv) leisure, (v) efficiency of investment, (vi) sectoral expenditure of the merchandised goods sector, and (vii) trade costs for each country-pair (i.e., shocks to trade-linkages).

Each country has two sectors: tradable merchandised goods and non-tradable services. Merchandise is traded between countries to create a composite good that combines home and foreign merchandise, while services are only consumed inside the country where they take place. A fraction of traded composite goods and services are used as intermediate inputs in this model; the rest is used in the production of the final good. The final good - an aggregate of traded composite merchandised goods and non-tradable services - is either consumed or invested. All tradable goods are subject to iceberg trade costs, as is commonly assumed in the international trade literature.

I calibrate the model to a set of developed countries (G7) and the rest of the world (ROW). ${ }^{2}$ There is no unexplained variation in the data - the shocks that I extract capture all of the variation in key business cycle observables. I match the model moments of GDP, gross production in merchandised goods, household consumption expenditure, labor hours, producer and consumer price indices, and bilateral trade shares all with their data counterparts. Subsequently, using the equilibrium conditions, I back out a set of structural shocks that completely describe the data from 1992-2014.

The business cycle accounting methodology I employ in my framework was first developed by Parkin (1988) and by Chari et al. (2007), and further extended by Eaton et al. (2016). Productivity shocks to the merchandised goods and non-tradable services sectors can be considered Solow residuals; they are obtained using GDP, gross production in merchandised goods, and the producer price indices of merchandised goods. Aggregate demand shocks encapsulate the underlying fluctuations in consumption expenditures, which are embedded in the model as time-varying preference wedges. Leisure shocks, which are another type of preference shock in the model, are backed out as a wedge from the marginal rate of substitution between consumption expenditure and labor. I obtain shocks to investment efficiency by using investment and consumption expenditures. Sectoral shocks to the expenditure of merchandised goods capture the shocks to demand in the goods sector relative to demand in the services sector in the final goods production; these shocks are backed out using input (PPI) and output (CPI) prices. All of that said, however, the most important shock in this paper is - the shock to trade-linkages. Trade-linkage shocks capture the underlying dynamic patterns of trade between country-pairs and are attained by matching bilateral trade shares of merchandised goods.

Equipped with the estimated shocks, I conduct counterfactual analyses to understand how each set of shocks contributes to cross-country business cycle synchronization. To isolate the contributions of each set of shocks, I re-calibrate the model by keeping one shock constant at a time, while feeding in the other shocks as they are backed out from the model. This allows me to measure how much each shock contributes to the cross-country GDP correlations by comparing the results to the cross-country GDP correlations from the data. The bigger the gap between the data and the counterfactual GDP correlations, the more impactful the shock is to the GDP co-movement.

\footnotetext{
${ }^{2}$ The G7 countries are Canada, France, Germany, Italy, Japan, the UK, and the US.
} 
I uncover several results. First, I find that trade-linkage shocks are primarily responsible for global business cycle synchronization. Other shocks play a minimal role in generating cross-country business cycle co-movement. A counterfactual scenario in which trade-linkage shocks are kept constant yields the most significant drop in cross-country GDP correlations compared to those from the data. I further analyze all of the results by dividing the sample into three periods: 1990s, early-2000s, and the (combined) Great Recession and post-recovery period. I find that trade-linkage shocks had the strongest impact in synchronizing business cycles during the early-2000s.

To delve more deeply into the causes of the trade-linkage shocks, I run counterfactual analyses wherein I hold one country's trade-linkage shocks constant while maintaining all the other trade-linkage shocks that do not involve the country of interest. ${ }^{3}$ I find that the trade-linkage shocks coming from the ROW the most important, followed by shocks in the United States and Germany. This finding suggests that the greater is the country's presence in global trade, the larger is that country's impact on international business cycle co-movement. Therefore, the variations in common trade with the ROW are found to generate international business cycle co-movement among the G7 countries.

The intuition behind why trade-linkage shocks affect global business cycle co-movement the most is the following: the trade-linkage shocks that I back out capture two components in the data - the decline in domestic shares of merchandise spending as countries are more open to trade, and fluctuations in bilateral trade flows. How I view trade-linkage shocks is different from the traditional view of trade-linkages in the literature. The previous literature views trade linkages as a shock-propagation channel; one country's shock propagates to another country through trade linkages. In this paper, though, trade-linkage shocks play an additional role: they are an exogenous component that hits both country-pairs simultaneously. Equipped with this additional aspect of the trade-linkage shocks, we can better understand the cross-country GDP co-movement that we observe in the data. This is consistent with my finding that the early-2000s were most affected by the trade-linkage shocks as we have observed a global boom in international trade with China's accession to the WTO. Furthermore, I then briefly discuss potential exogenous sources that could be driving the trade-linkage shocks in the data.

I show that the trade-linkage shocks are crucial in resolving the trade co-movement puzzle. The trade co-movement puzzle, which was first proposed by Kose and Yi (2006), states that the standard international macroeconomic models cannot capture the increase in GDP correlations as trade increases between the trading partners that is found in the data. My findings shed light on this by suggesting that the reason why standard macroeconomic models fail to resolve the puzzle is because the previous literature did not account for the trade-linkage shocks that hit country-pairs simultaneously. Other country-specific shocks, including productivity shocks, do not affect the GDP co-movement when trade increases. Accordingly, my model shows that without trade-linkage shocks, the model's bilateral trade shares do not reflect the growth and fluctuations of international trade. In other words, the changing nature of economic integration and the volatility of bilateral trade flows are the missing piece of the trade co-movement puzzle. In their work that started this strand of literature, Frankel and Rose (1998) write, "the large IRBC literature, which endogenize output correlations [...] does not focus on the effects of changing economic integration." Indeed, my results show that the previous literature has been missing the dynamic aspect of trade. Previous research has largely focused on calibrating models to steady-state import trade shares, an approach that does not capture the

\footnotetext{
${ }^{3}$ The country-specific correlated shocks still vary in these exercises.
} 
complex evolutionary process of trade shocks.

This paper contributes mainly to three lines of literature. First, it contributes to the literature on the determinants of international business cycles and cross-country business cycle synchronization. Ever since Backus et al. (1992)'s seminal paper on an extension of a real business cycle model to a two-country, large open economy, research on international business cycles has diverged in two different ways, ${ }^{4}$ and a large portion of that literature studies how the correlated, country-specific shocks affect international business cycles. On the one hand, Imbs (2004) argues that country-specific correlated shocks are responsible for business cycle co-movement. There have been numerous studies on other types of correlated shocks besides correlated productivity shocks. ${ }^{5}$ On the other hand, Frankel and Rose (1998) and Baxter and Kouparitsas (2005) find that countries that trade more with each other have a higher degree of business cycle synchronization, which suggests that trade may be essential in understanding international co-movements. ${ }^{6}$ I contribute to this literature by incorporating all of the shocks in competing hypotheses to determine which shock makes the largest contribution to the synchronization of international business cycles.

Secondly, as alluded to above, this paper contributes to the literature on the trade co-movement puzzle. First proposed by Kose and Yi (2006), the trade co-movement puzzle describes that standard IRBC models fail to generate higher cross-country GDP synchronization when country-pairs increase their trade as in the data. Specifically, in standard IRBC models, Kose and Yi (2006) find that cross-country GDP correlations are largely unresponsive to changes in trade. A large portion of the related literature has examined how to amplify the shock propagation from one country to another by introducing different shock-amplification mechanisms. ${ }^{7}$ I contribute to this literature by showing that models need a mechanism for capturing the dynamics of bilateral trade shocks between trading partners. Furthermore, I offer a brief intuition in linking my results to the existing literature on the trade co-movement puzzle.

Finally, this paper adds to the vast literature that study the impacts of various shocks on macroeconomic aggregates by a business cycle accounting methodology that was first developed by Parkin (1988) and by Chari et al. (2007). Since then, the methodology has been applied to open economy studies by Eaton et al. (2016), Reyes-Heroles (2017), and Ohanian et al. (2018). ${ }^{8}$ Building on these previous studies, my paper further highlights that trade shocks (trade-linkages) are important when considering international co-movements.

The rest of the paper proceeds as follows: Section 2 discusses paper's empirical motivation. Section 3 details the international real business cycles model that incorporates various shocks, while Section 4 describes the model calculation. Section 5 describes the accounting procedure and provides which variables

\footnotetext{
${ }^{4}$ Backus et al. (1992) find that only with correlated TFP shocks, the two-country IRBC model does not match international co-movements of output and consumption very well, thus becoming a starting point of various international macroeconomic puzzles.

${ }^{5}$ Stockman and Tesar (1995) incorporate shocks to preferences to explain international co-movements of output and consumption across countries. Huo et al. (2019) embed non-TFP shocks, which is similar to the labor/leisure shocks in my paper. Raffo (2010) argues that investment technology shocks drive international business cycles.

${ }^{6}$ Alessandria et al. (2013) and Engel and Wang (2011) conclude that bilateral trade cost shocks are the key source of cross-country business cycles.

${ }^{7}$ Burstein et al. (2008) introduce Leontiff production with global value chains, and Johnson (2014) extends the IRBC model with input-output linkages, but both of these papers fail to generate the coefficient (slope) that is seen from the empirical regression. Liao and Santacreu (2015) and de Soyres and Gaillard (2019) argue that a Melitz-type model, with extensive margin of trade and love for variety, resolves the puzzle. Drozd et al. (2019) argue that when trade elasticity varies across time, the puzzle is alleviated.

${ }^{8}$ Eaton et al. (2016) studies the role of various macroeconomic shocks to the trade collapse during the Great Recession, and Reyes-Heroles (2017) studies the role that a decline in trade costs plays with respect to the global trade imbalances. Ohanian et al. (2018) studies the changes in capital flows in Latin America and Asia.
} 
are matched with the data. Section 6 describes the data and the main results. Section 7 discusses application to the trade co-movement puzzle and links the results to the existing literature. Section 8 briefly discusses the potential sources of trade-linkage shocks, and Section 9 concludes.

\section{Empirical Motivation}

In this section, I document the international business cycle synchronization from the past three decades. First, I plot the average of cross-country correlations of real GDP growth rates for every possible pair among the G7 countries and the rest of the world (ROW). Figure 1 shows the trend in global business cycle synchronization in three waves: the 1990s, the early-2000s, and the combined Great Recession and the post-recovery period. I note that cross-country business cycles are synchronized across countries, on average. However, I also observe an increase in the trend; cross-country business cycles have become more synchronized over the past three decades. Figure 1 shows that there has been a stark increase in global business cycle synchronization from 2000 to 2007.

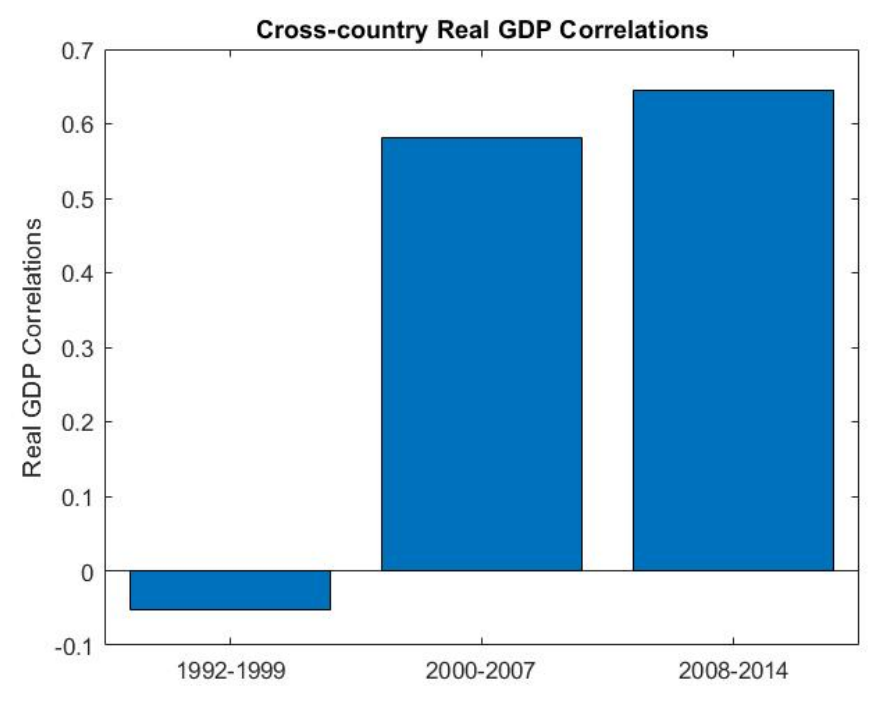

Figure 1: Real GDP Correlations between G7 and ROW

Going deeper into the data, I then analyze the GDP co-movement between individual country pairs. Table 10 in the appendix summarizes the country-pair correlations of real GDP growth rates, and I observe a heterogeneity in the evolution of cross-country business cycle synchronization. Looking at the 1990s, I observe, specifically, that cross-country GDP correlations among the G7 countries (except for Japan) are positively synchronized; the average cross-country GDP co-movement is close to zero in the 1990s because Japan and the ROW are not in synchronization with the rest of the G7. In contrast, the business cycles of Canada, Germany, France, the United Kingdom, Italy, and the United States are positively synchronized, even as early as the 1990s. The global synchronization in the early-2000s, then, becomes starker when the business cycles of Japan and the ROW synchronize with the other G7 countries.

Global business cycle co-movement has been affected by a series of events across the world. First, there 


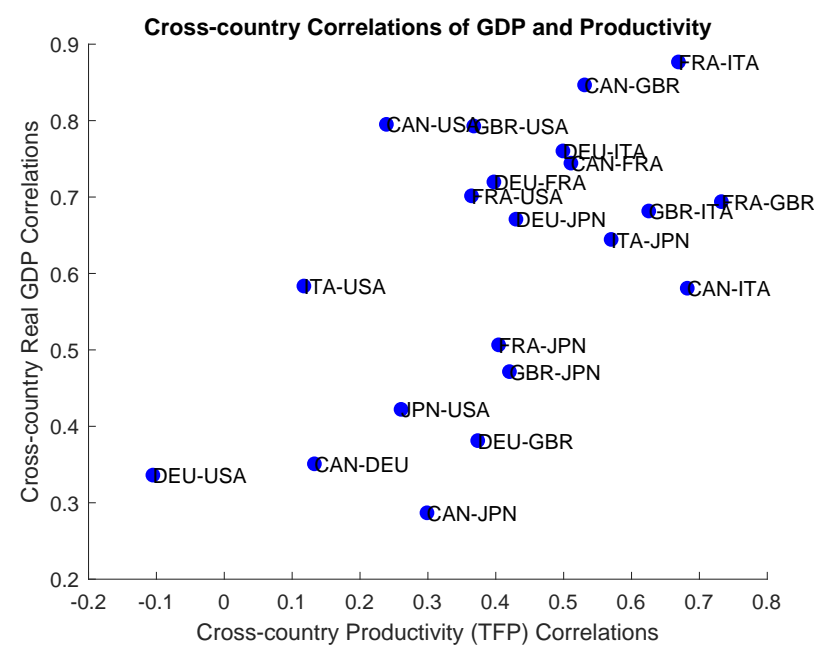

Panel A

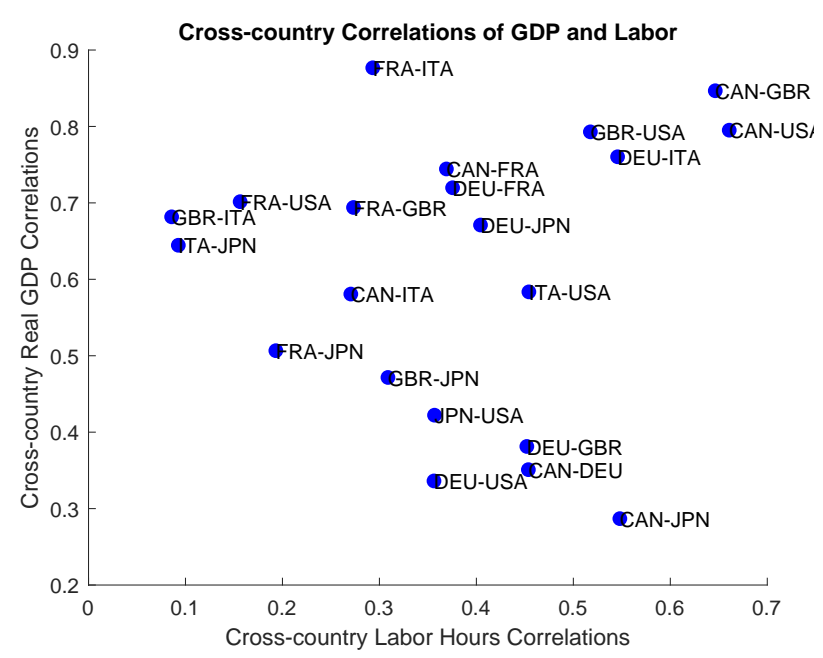

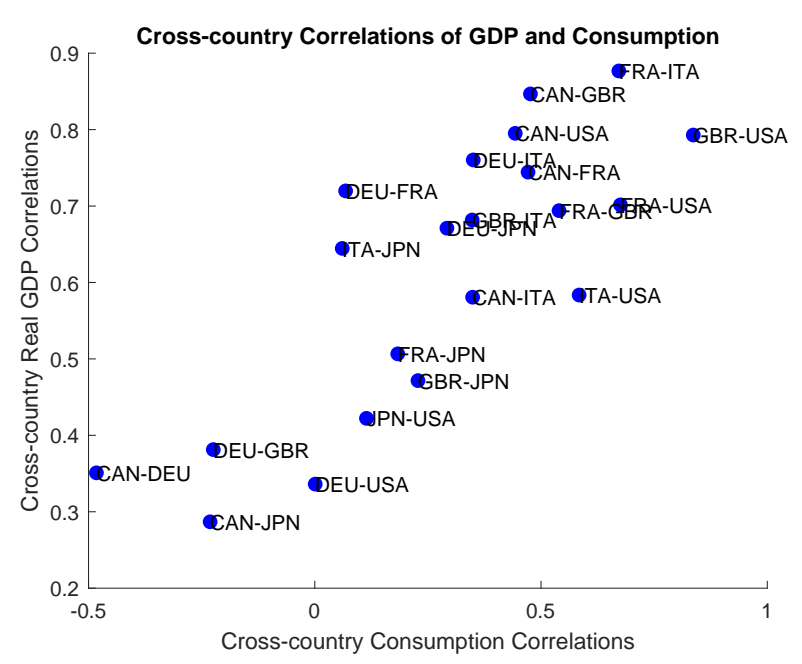

Panel B

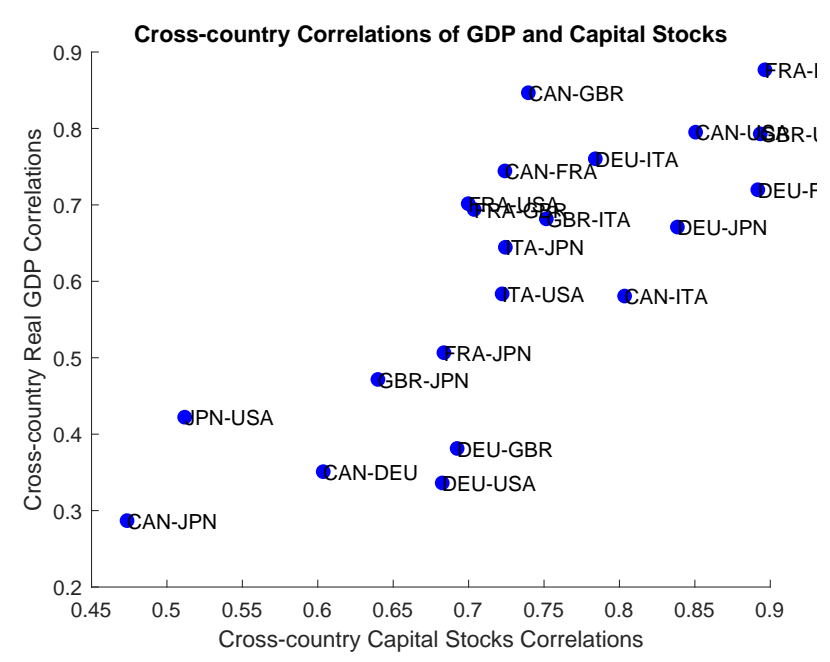

Panel D

Panel C

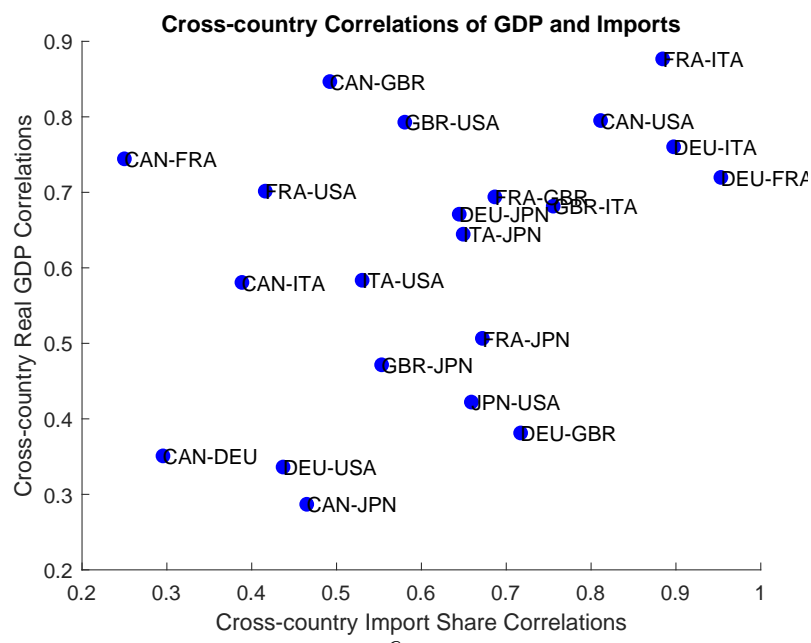

6

Panel E

Figure 2: Cross-country Real GDP Correlations vs. Cross-country Co-movements of TFP, Consumption, Labor, Capital, and Imports 
has been a global boom in international trade as many developing countries, including China, have emerged onto the global trade market. Furthermore, many countries, especially developed economies, have become more similar in their production and their demand composition. Likewise, investments across developed economies have become more correlated with each other, and many economies have experienced structural changes from the manufacturing to the services sectors.

In Figure 2, as a set of suggestive evidence, I separately plot the various factors that affected the business cycle synchronization from 1992 to 2014. In panel A of Figure 2, I plot country pairwise real GDP correlations and the pairwise productivity (TFP) correlations among the G7 countries. (Here and in what follows in this section is the data from 1992 to 2014.) I find that the more correlated the productivities are, the higher the correlations of real GDP across countries. As mentioned in the introduction, people have looked into how correlated TFP shocks affect international business cycle co-movement. Panel B, C, and D show the correlations of consumption, labor hours, and capital stocks with the cross-country GDP correlations, respectively. Furthermore, we also observe that higher the import correlations are, GDP correlations are much more synchronized, shown by Panel E of Figure 2. ${ }^{9}$ Therefore, this panel shows that economic integration contributed to the international business cycles and that the country-specific factors have become more correlated. However, to disentangle these forces, we need a structural model that can incorporate all of these factors to understand what drives the synchronization of global business cycles.

\section{A Dynamic IRBC Model with Trade in Merchandise}

To disentangle the effects of international trade from other country-specific shocks, I build an international real business cycle model that captures international trade in merchandise. ${ }^{10}$

In this model, there are $N$ countries, and for each country, there is a representative agent. Each country also has two sectors: the merchandise $(G)$ and services $(S)$ sectors. Merchandised goods are internationally traded while services are not tradable. ${ }^{11}$ Each country completely specializes in producing both tradable goods and non-tradable services. ${ }^{12}$ Final good production, meanwhile, is an aggregate of merchandised goods and services using Armington technology, and the final good that is produced is either consumed or invested in the capital stock.

There are multiple shocks in this model: shocks to productivity in tradable and non-tradable sectors, aggregate demand, leisure, investment, sectoral expenditure on merchandise, and bilateral trade costs. ${ }^{13}$ I assume that agents have perfect foresight. With perfect competition and asset market completeness, I interpret the model as a global social planner's problem and I solve for the planner's allocations. In this section, I discuss the details of the model and the solutions to the social planner's problem.

\footnotetext{
${ }^{9}$ The same panel for the entire set of OECD countries are in Figure 8 of the Appendix.

${ }^{10}$ Merchandised goods consist of primary (agriculture and mining) and manufacturing goods.

${ }^{11}$ This is not entirely true of the current digital age. However, to address the concern that a country may be too open in the model compared to the data, I impose this model restriction.

${ }^{12}$ This assumption arises from the IRBC framework.

${ }^{13}$ Shocks in the model are the red-colored variables in the model.
} 


\subsection{Production}

Intermediate Production. There are two sectors in each country: merchandised goods $(G)$ and services $(S)$. Intermediate merchandised goods are traded across countries while goods produced in service sector are not traded. The intermediate production function for sector $j$ is defined as

$$
y_{n, t}^{j}=z_{n, t}^{j}\left[\left(L_{n, t}^{j}\right)^{\alpha_{n}}\left(K_{n, t}^{j}\right)^{1-\alpha_{n}}\right]^{\beta_{n}^{j}}\left(\left(M_{n, t}^{j j}\right)^{\gamma_{n}^{j}}\left(M_{n, t}^{j j^{\prime}}\right)^{1-\gamma_{n}^{j}}\right)^{1-\beta_{n}^{j}} .
$$

To produce output $y_{n, t}^{j}$ in sector $j \in\{G, S\}$, country $n$ uses labor $L_{n, t}^{j}$, capital $K_{n, t}^{j}$, and a bundle of intermediates $\left(M_{n, t}^{j j}\right)^{\gamma_{n}^{j}}\left(M_{n, t}^{j j^{\prime}}\right)^{1-\gamma_{n}^{j}}$. Country-specific labor share of output in country $n$ is denoted by $\alpha_{n}$. The share of value-added in producing sectoral good $j$ in country $n$ is defined as $\beta_{n}^{j}$. For a bundle of intermediate inputs, $\gamma_{n}^{j}$ denotes the share of how much sector $j$ 's goods is used as its own intermediates. Hence, $1-\gamma_{n}^{j}$ portion of intermediate bundle in sector $j$ comes from sector $j^{\prime}$.

For intermediate input bundle, $M^{j j^{\prime}}$ is the intermediates from sector $j^{\prime}$ that are used to make sector $j$ goods. $z_{n, t}^{j}$ denotes productivity shock to sector $j$ in country $n$. Labor is defined as $L_{n, t}^{j}=l_{n, t}^{j} N_{n, t}$, where $N_{n, t}$ is total population of country $n$ at time $t$.

Composite Tradable Goods. A portion of merchandised goods are traded across countries to form a composite bundle of intermediate good $T R_{n, t}^{G}{ }^{14}$. This composite traded bundle takes a form using Armington technology

$$
T R_{n, t}^{G}=\left[\sum_{i=1}^{N}\left(m_{n i, t}^{G}\right)^{\sigma}\right]^{\frac{1}{\sigma}}
$$

where

$$
m_{n i, t}^{G} \equiv \frac{1}{d_{n i, t}^{G}} y_{n i, t}^{G}
$$

$y_{n i, t}^{G}$ is a quantity of merchandised goods exports that country $i$ ships to country $n$, and $m_{n i, t}^{G}$ is a quantity of imports that arrive at $n$ from $i$. Imported intermediates $m_{n i, t}^{G}$ are subject to trade frictions, which are specific to country pair $(i, n) . d_{n i, t}^{G}$ is bilateral trade cost shocks for tradable merchandised goods, similar to the standard iceberg costs, where $d_{n i, t}^{G}>1$ if $n \neq i$ and $d_{i i, t}=1$. The elasticity of substitution between home and foreign intermediate goods, $\frac{1}{1-\sigma}$, is a key parameter that determines how substitutable imported goods are from home goods.

Feasibility Conditions for Goods and Services Sectors. After merchandises are traded, merchandised goods bundle $T R_{n, t}^{G}$ is used to create final goods or used as intermediate inputs. Denoting $F_{n, t}^{G}$ as

\footnotetext{
${ }^{14}$ With a lack of better notation, TR stands for "tradables."
} 
merchandise that are used to make final goods, the equation

$$
T R_{n, t}^{G}=F_{n, t}^{G}+M_{n, t}^{G G}+M_{n, t}^{S G}
$$

is the feasibility constraint for merchandise sector. The same logic applies to the service sector. Keeping in mind that the service sector is non-tradable, the total service production $y_{n, t}^{S}$ is used to to create final good $\left(F_{n, t}^{S}\right)$, or are used as intermediate inputs to merchandised goods $\left(M_{n, t}^{G S}\right)$ or itself (services) $\left(M_{n, t}^{S S}\right)$, where the feasibility condition

$$
y_{n, t}^{S}=F_{n, t}^{S}+M_{n, t}^{S S}+M_{n, t}^{G S}
$$

has to hold. The final feasibility condition is about the world usage of merchandised goods output, which is expressed by

$$
y_{n, t}^{G}=\sum_{i=1}^{N} d_{i n, t}^{G} m_{i n, t}^{G}
$$

where (6) expresses the use of merchandised goods from country $n$ at time $t$ has to be equal to what $n$ produces.

Final Goods Production. A portion of merchandised goods $F_{n, t}^{G}$ and a portion of non-traded services goods $F_{n, t}^{S}$ are aggregated to produce final goods which are used for consumption and investment. The final goods production function uses Armington technology to produce $F_{n, t}$,

$$
F_{n, t}=\left[\left(\theta_{n, t}\right)^{1-\mu}\left(F_{n, t}^{G}\right)^{\mu}+\left(y_{n, t}^{S}\right)^{\mu}\right]^{\frac{1}{\mu}}
$$

where $\theta_{n, t}$ governs shocks to relative demand for tradable merchandised goods sector to non-tradable services sector, which I call sectoral shocks. The elasticity of substitution between traded merchandises and nontradable services is $\frac{1}{\mu-1}$.

\subsection{Households}

In each period $t$ the representative household in country $n$ consumes some portion of the final goods, denoted as $C_{n, t}$, and chooses the amount of leisure time $\left(1-l_{n, t}\right)$. The lifetime utility of the representative agent in country $n$ is

$$
U_{n}=\sum_{t=0}^{\infty} \rho^{t} \phi_{n, t}\left(\log \left(C_{n, t}\right)+\xi_{n, t} \log \left[N_{n, t}\left(1-l_{n, t}\right)\right]\right)
$$

where $\rho$ is a constant discount factor, and $\phi_{n, t}$ is an aggregate demand shock. I denote $\xi_{n, t}$ as a leisure shock, which acts as a wedge between the marginal rate of substitution between consumption and leisure. 
$N_{n, t}$ is a total population of country $n$ at time $t$. This is multiplied with leisure for accounting purposes. ${ }^{15}$

\subsection{Capital Dynamics}

The aggregate capital $K_{n, t}$ evolves according to the following law of motion for capital:

$$
K_{n, t+1}=(1-\delta) K_{n, t}+\chi_{n, t} I_{n, t}
$$

where $\delta$ is the depreciation rate. Aggregate capital is defined as $K_{n, t}=K_{n, t}^{M}+K_{n, t}^{S} \cdot \chi_{n, t}$ are shocks to efficiency of investment. This type of shock is first introduced by Greenwood et al. (1988), and has been discussed in the previous literature as the key driver of the closed-economy business cycles.

\subsection{Solving Social Planner's Problem}

I assume that asset markets are complete. Furthermore, people have perfect foresight. This allows me to solve for the market allocations as a global social planner's problem in which the market allocations are efficient. Thus, the resource allocations by the social planner are supported by the competitive equilibrium allocations.

The planner's objective at time 0 is to maximize

$$
W=\sum_{n=1}^{N} \omega_{n} U_{n}
$$

given the initial levels of aggregate capital $K_{n, 0}$ for each country $n$, where $\omega_{n}$ is a country weight that the social planner assigns to each country. ${ }^{16}$ The details of how I solve for the planner's allocations are in the appendix of this paper.

\subsection{Linking Planner's Allocations to Equilibrium Allocations}

In the appendix, I solve the global social planner's problem, which delivers the market allocations for each country. I interpret the shadow prices in the Lagrangian optimization problem as competitive intermediate prices $p_{n, t}^{j}$ for each sector $\{G, S\}$, composite tradable and non-tradable goods price indices $q_{n, t}^{G}$ and $q_{n, t}^{S}$, final good price index $q_{n, t}$, wages $w_{n, t}$, and rental rates $r_{n, t}$ for each country $n$. All allocations of the social planner's problem are equivalent to the competitive equilibrium allocations as shown in Lucas and Prescott (1971).

(i) Intermediate price of non-tradable services sector of country $n$ at time $t$ is

\footnotetext{
${ }^{15}$ Population is a shock that is treated as exogenous.

${ }^{16}$ Note that $\omega_{n}$ is time-invariant. This is an important feature in the model, as this assumption will be useful in invoking the business cycle accounting methodology later.
} 


$$
p_{n, t}^{S}=\frac{B^{S}\left[\left(w_{n, t}\right)^{\alpha_{n}}\left(r_{n, t}\right)^{1-\alpha_{n}}\right]^{\beta_{n}^{S}}\left[\left(p_{n, t}^{S}\right)^{\gamma_{n}^{S}}\left(q_{n, t}^{G}\right)^{1-\gamma_{n}^{S}}\right]^{1-\beta_{n}^{S}}}{z_{n, t}^{S}}
$$

The cost of a bundle of inputs for services sector, $B^{S}$, combines labor, capital, and the price bundles for intermediate input usage. The intermediate price index $p_{n, t}^{S}$ is equal to its marginal cost. ${ }^{17}$

(ii) Intermediate price of tradable, merchandised goods sector of country $n$ at time $t$ is

$$
p_{n, t}^{G}=\frac{B^{G}\left[\left(w_{n, t}\right)^{\alpha_{n}}\left(r_{n, t}\right)^{1-\alpha_{n}}\right]^{\beta_{n}^{G}}\left[\left(q_{n, t}^{G}\right)^{\gamma_{n}^{G}}\left(p_{n, t}^{S}\right)^{1-\gamma_{n}^{G}}\right]^{1-\beta_{n}^{G}}}{z_{n, t}^{G}}
$$

The cost of a bundle of inputs for goods sector, $B^{G}$, combines wages, rental rates, and prices for intermediate input usages. I denote $z_{n, t}^{G}$ as TFP shocks to the merchandised goods sector, so $p_{n, t}^{G}$ is equal to its marginal cost. Since labor and capital are freely mobile inside each country, wages and rental rates are equalized between the two sectors. ${ }^{18}$

(iii) The composite tradable goods price index $q_{n, t}^{G}$ is given by

$$
q_{n, t}^{G}=\left[\sum_{i=1}^{N}\left(p_{i, t}^{G} d_{n i, t}^{G}\right)^{\frac{\sigma}{\sigma-1}}\right]^{\frac{\sigma-1}{\sigma}}
$$

where $p_{i, t}^{G}$ is the intermediate price for merchandised goods defined in (12). Merchandised goods price index of country $n$ accounts for the production costs in each country subject to bilateral trade shocks that are country-pairwise. When there are shocks in foreign country, it propagates through the foreign price index $p_{i, t}^{G}$. Further, as trade frictions $d_{n i, t}^{G}$ increase, ceteris paribus, the intermediate input price index increases. I interpret the fluctuations in $d_{n i, t}^{G}$ as bilateral trade cost shocks between country-pair $n$ and $i$.

(iv) Final goods price index $q_{n, t}$ for country $n$ is given by

$$
q_{n, t}=\left(\theta_{n, t}\left(q_{n, t}^{G}\right)^{\frac{\mu}{\mu-1}}+\left(p_{n, t}^{S}\right)^{\frac{\mu}{\mu-1}}\right)^{\frac{\mu-1}{\mu}}
$$

$$
\begin{aligned}
& { }^{17} B^{S} \text { is defined as } B^{S}=\left[\left(\alpha_{n} \beta_{n}^{S}\right)^{-\alpha_{n}}\left(\left(1-\alpha_{n}\right) \beta_{n}^{S}\right)^{-\left(1-\alpha_{n}\right)}\right]^{\beta_{n}^{S}}\left[\left(\gamma_{n}^{S}\left(1-\beta_{n}^{S}\right)\right)^{-\gamma_{n}^{S}}\left(\left(1-\gamma_{n}^{S}\right)\left(1-\beta_{n}^{S}\right)\right)^{-\left(1-\gamma_{n}^{S}\right)}\right]^{1-\beta_{n}^{S}} \\
& { }^{18} B^{G} \text { is defined as } B^{G}=\left[\left(\alpha_{n} \beta_{n}^{G}\right)^{-\alpha_{n}}\left(\left(1-\alpha_{n}\right) \beta_{n}^{G}\right)^{-\left(1-\alpha_{n}\right)}\right]^{\beta_{n}^{G}}\left[\left(\gamma_{n}^{G}\left(1-\beta_{n}^{G}\right)\right)^{-\gamma_{n}^{G}}\left(\left(1-\gamma_{n}^{G}\right)\left(1-\beta_{n}^{G}\right)\right)^{-\left(1-\gamma_{n}^{G}\right)}\right]^{1-\beta_{n}^{G}}
\end{aligned}
$$


where $\theta_{n, t}$ represents sectoral shocks to traded merchandised goods. If $\theta$ increases, the share of merchandised goods sector increase relative to the non-tradable services sector.

(v) The share of country n's expenditure on merchandised goods sector $G$, imported from country $i$ is

$$
\pi_{n i, t}^{G}=\left(\frac{p_{i, t}^{G} d_{n i, t}^{G}}{q_{n, t}^{G}}\right)^{\frac{\sigma}{\sigma-1}}
$$

$\pi_{n i, t}^{G}$ is defined as country $n$ 's imported trade shares coming from country $i$, where $\sum_{i=1}^{N} \pi_{n i, t}^{G}=1$. The trade shares $\pi_{n i, t}^{G}$ depends on the intermediate price index $p_{n, t}^{G}$. The spillover from a foreign shock, regardless of what it is, happens through $p_{i, t}^{G}$. On the other hand, if there are shocks that affect the particular country-pair, changes would appear in bilateral trade shocks $d_{n i, t}^{G}$.

(vi) The marginal rate of substitution between consumption and leisure is given by

$$
w_{n, t}\left(1-l_{n, t}\right) N_{n, t}=\xi_{n, t} q_{n, t} C_{n, t}
$$

The leisure shock $\xi_{n, t}$ appears as part of the marginal rate of substitution between consumption and leisure. $\xi_{n, t}$ not only affects the allocations of labor hours and wages today but also across time.

(vii) Household spending on consumption goods is

$$
q_{n, t} C_{n, t}=\omega_{n} \phi_{n, t}
$$

which depends on the country weight $\omega_{n}$, which is time-invariant, and aggregate demand shock $\phi_{n, t}$. $\phi_{n, t}$ captures changes to preferences of consumers in country $n$, or it could be interpreted as the changes in saving behaviors of consumers in country $n$. If the aggregate demand shock $\phi_{n, t}$ increases, the consumption expenditure of the households increases at time $t$.

(viii) The Euler equation for each country $n$ is

$$
\frac{q_{n, t}}{\chi_{n, t}}=\rho\left[\frac{q_{n, t+1}}{\chi_{n, t+1}}(1-\delta)+r_{n, t+1}\right]
$$

where $q_{n, t}$ is final good price index, and $r_{n, t+1}$ is rental rate of capital at time $t+1$. The left-hand side of the Euler equation represents the value of the final good that should be given up to make future investments, and the right-hand side is the benefit of using that investment in the next period. $\chi_{n, t}$ is a shock to investment efficiency. If the investment is completely efficient (a standard IRBC model), then $\chi_{n, t}$ would disappear from the equation, and there would not be any distortion to the final good price index. 
(ix) I define $Y_{n, t}^{G}=p_{n, t}^{G} y_{n, t}^{G}$ to be the total gross production of country $n$ in merchandised goods, and $X_{n, t}^{G}=p_{n, t}^{G} x_{n, t}^{G}$ to be total value of expenditure (absorption) on merchandised goods of country $n$. In this way, I can write the world merchandised goods market clearing as the flow of traded intermediate merchandised goods in terms of their values.

$$
Y_{n, t}^{G}=\sum_{i \in N} X_{i n, t}^{G}=\sum_{i \in N} \pi_{i n, t}^{G} X_{i, t}^{G}
$$

where $X_{i n, t}^{G}$ is how much country $i$ spends on its traded merchandised goods that come from country $n$. Summing the expenditures on traded merchandised goods that come from country $n$, it must be equal to the total value of gross production merchandised goods of country $n$.

(x) Define $X_{n, t}^{F, G}=q_{n, t}^{G} F_{n, t}^{G}$ to be the expenditure on merchandised goods in country $n$ that is used to produce final goods. The total expenditure on merchandised goods sector is the sum of country $n$ 's the spending on merchandised goods in producing final goods plus spending on purchasing the intermediate input bundle in merchandised goods production.

$$
X_{n, t}^{G}=X_{n, t}^{F, G}+\left(1-\beta_{n}^{G}\right)\left(\gamma_{n}^{G}\right) Y_{n, t}^{G}+\left(1-\beta_{n}^{S}\right)\left(1-\gamma_{n}^{S}\right) Y_{n, t}^{S}
$$

(xi) Define $X_{n, t}^{F, S}=p_{n, t}^{S} F_{n, t}^{S}$ to be the expenditure on services in country $n$ that is used to produce final goods. The total expenditure on services sector is the sum of country $n$ 's the spending on services in producing final goods plus the spending on purchasing the intermediate input bundle in services production.

$$
X_{n, t}^{S}=X_{n, t}^{F, S}+\left(1-\beta_{n}^{G}\right)\left(1-\gamma_{n}^{G}\right) Y_{n, t}^{G}+\left(1-\beta_{n}^{S}\right)\left(\gamma_{n}^{S}\right) Y_{n, t}^{S}
$$

(xii) Define $X_{n, t}^{F}=q_{n, t} F_{n, t}$ to be the total spending (absorption) on final goods which is equal to $X_{n, t}^{F}=$ $X_{n, t}^{F, M}+X_{n, t}^{F, S}$. The total spending on producing final goods is either used as purchasing final consumption goods or as investing in future capital stocks:

$$
X_{n, t}^{F}=X_{n, t}^{C}+X_{n, t}^{I}
$$

where $X_{n, t}^{C}=q_{n, t} C_{n, t}$ and $X_{n, t}^{I}=q_{n, t} I_{n, t}$.

(xiii) Define $Y_{n, t}$ to be the GDP of country $n$ at time $t$. I use production approach to calculate GDP in this model. The gross value of domestic output is equal to the sum of merchandised goods and services output $Y_{n, t}^{G}+Y_{n, t}^{S}$. To calculate GDP, we only need to take into account the value-added portion of domestic output in merchandised goods. Hence, I define GDP as 


$$
Y_{n, t}=\beta_{n}^{G} Y_{n, t}^{G}+\beta_{n}^{S} Y_{n, t}^{S}
$$

where $\beta_{n}^{j}$ is the value-added share of the gross production in sector $j$.

(xiv) Labor market clearing. The labor income is equal to labor demand every period.

$$
w_{n, t} l_{n, t} N_{n, t}=\alpha_{n} \beta_{n}^{G} Y_{n, t}^{G}+\alpha_{n} \beta_{n}^{S} Y_{n, t}^{S}=\alpha_{n} Y_{n, t}
$$

where $Y_{n, t}=\beta_{n}^{G} Y_{n, t}^{G}+\beta_{n}^{S} Y_{n, t}^{S}$.

(xv) Capital market clearing. The capital income is equal to capital demand every period.

$$
r_{n, t} K_{n, t}=\left(1-\alpha_{n}\right) \beta_{n}^{G} Y_{n, t}^{G}+\left(1-\alpha_{n}\right) \beta_{n}^{S} Y_{n, t}^{S}=\left(1-\alpha_{n}\right) Y_{n, t}
$$

where $Y_{n, t}=\beta_{n}^{G} Y_{n, t}^{G}+\beta_{n}^{S} Y_{n, t}^{S}$.

The equations from (i) - (xv) reflect all of the equilibrium relationships and market clearing conditions from the global social planner's problem. To perform the accounting procedure, I allow for exogenous debt process for services sector, $D_{n, t}^{S}$, where $D_{n, t}^{S}=Y_{n, t}^{S}-X_{n, t}^{S}$ and $\sum_{i=1}^{N}\left(D_{n, t}^{M}+D_{n, t}^{S}\right)=0$.

\subsection{Steady State of the Equilibrium with Perfect Foresight}

I define the steady state of the perfect foresight economy of the social planner's problem. First, I collect the shocks in the model, which I define as $\Psi_{t}$ :

$$
\Psi_{t}=\left\{z_{n, t}^{G}, z_{n, t}^{S}, \phi_{n, t}, \xi_{n, t}, \chi_{n, t}, \theta_{n, t}, d_{n i, t}^{G}, D_{n, t}^{S}, N_{n, t}\right\}
$$

These shocks are time-varying. To find the steady state, I assume that the shocks are constant and the capital stocks, $K_{n, t}$, have settled down to constant levels of $K_{n}$. Hence the steady state of the model has to satisfy the capital and investment spending ratio

$$
\frac{r_{n} K_{n}}{X_{n}^{I}}=\frac{1-\rho+\rho \delta}{\rho \delta}
$$

and the capital accumulation equation becomes

$$
\frac{I_{n}}{K_{n}}=\frac{\delta}{\chi_{n}}
$$

and all the outcomes from the equilibrium relationships are satisfied. 


\section{Model Calculation}

Here, I briefly discuss how I calculate the model, given the initial parameters and exogenous shocks. I follow the hat-algebra method by Dekle et al. (2007) to solve the model exactly.

\subsection{Initial Parameters and Exogenous Shocks}

There are parameters that are time-invariant, which I denote as $\Omega$.

$$
\Omega=\left\{\alpha_{n}, \beta_{n}^{j}, \gamma_{n}^{j}, \sigma, \rho, \mu, \beta\right\}
$$

I denote time-varying shocks to be $\widehat{\Psi}_{t+1}$.

$$
\Psi_{t}=\left\{z_{n, t}^{G}, z_{n, t}^{S}, \phi_{n, t}, \xi_{n, t}, \chi_{n, t}, \theta_{n, t}, d_{n i, t}^{G}, N_{n, t}, D_{n, t}^{S}\right\}
$$

Using the set of time-invariant initial parameters $\Omega$ and the set of time-varying structural shocks $\Psi_{t}$, I show the algorithm to calculate the endogenous outcomes of the equilibrium, which is laid out in detail in the Appendix D.

\subsection{Calculating Endogenous Outcomes of the Model}

Equipped with the initial parameters and structural shocks, the paths of the endogenous outcomes of the model can be calculated. Let's say that the initial period starts at time $t$, and we want to calculate the endogenous outcomes of the model in time $t+1$. Given the initial values of GDP $\left(Y_{n, t}\right)$, gross production in merchandised goods $\left(Y_{n, t}^{G}\right)$, labor hours $\left(l_{n, t}\right)$, trade shares of merchandised goods $\left(\pi_{n i, t}^{G}\right)$, expenditure on consumption goods $\left(X_{n, t}^{C}\right)$, changes to capital $\left(\widehat{K}_{n, t+1}\right)$, and the paths of shocks $\widehat{\Psi}_{t+1}$ in changes, I recover the next period's endogenous outcomes. In other words, using $\widehat{\Psi}_{t+1}$, I can calculate the next period's GDP $\left(Y_{n, t+1}\right)$, gross production of merchandised goods $\left(Y_{n, t+1}^{G}\right)$, labor hours $\left(l_{n, t+1}\right)$, bilateral trade shares $\left(\pi_{n, t+1}^{G}\right)$, and consumption spending $\left(X_{n, t+1}^{C}\right)$, and changes to capital $\left(\widehat{K}_{n, t+2}\right)$.

Given the initial values of GDP $\left(Y_{n, t}\right)$, gross production in merchandised goods $\left(Y_{n, t}^{G}\right)$, labor hours $\left(l_{n, t}\right)$, trade shares of merchandised goods $\left(\pi_{n i, t}^{G}\right)$, expenditure on consumption goods $\left(X_{n, t}^{C}\right)$, and changes to capital $\left(\widehat{K}_{n, t+1}\right)$ - and equipped with the equations in Appendix D - I can calculate the next period's $\operatorname{GDP}\left(Y_{n, t+1}\right)$, gross production in merchandised goods and services $\left(Y_{n, t+1}^{j}\right.$ for $\left.j\{G, S\}\right)$, labor hours $\left(l_{n, t+1}\right)$, consumption spending $\left(X_{n, t+1}^{C}\right)$, imported trade shares $\left.\pi_{n i, t+1}\right)$, and subsequent capital stocks in changes $\left(\widehat{K}_{n, t+2}\right)$. I then repeat this process for the next period. ${ }^{19}$

\section{Accounting Procedure}

The allocations from the social planner's problem, with the market clearing conditions, completely describe the market allocations of the global economy. Using the methodology developed by Parkin (1988) and Eaton et al. (2016), I choose shocks so that the equilibrium outcomes of the model match the data.

\footnotetext{
${ }^{19}$ The details of the model calculations is in Appendix D of this paper.
} 


\begin{tabular}{llll}
\hline Parameters & Description & Value & Source \\
\hline \hline$\alpha_{n}$ & Labor share in production & - & Data (PWT 9.1) \\
$\beta_{n}^{j}, j \in\{G, S\}$ & value-added to gross output ratio & - & Data (OECD STAN) \\
$\gamma_{n}^{j}, j \in\{G, S\}$ & Input-output shares & - & Data (WIOT) \\
$\delta$ & Depreciation rate & 0.05 & Standard annual rate \\
$\rho$ & Discount factor & 0.96 & Kose \& Yi (2006) \\
$\sigma$ & Elasticity of substitution between foreign intermediates & 0.333 & Kose \& Yi (2006) \\
$\eta$ & Goods vs. services elasticity & 0.5 & Johnson (2014) \\
\hline
\end{tabular}

Table 1: Time-Invariant Parameters of the Model

\subsection{Initial Parameters of the Model}

To perform the business cycle accounting procedure, I first calibrate the model's initial parameters. The discount factor for the utility function $\rho$ is 0.96, which is taken directly from Backus et al. (1992) and Kose and Yi (2006). The labor shares for production functions (the Cobb-Douglas labor share) are taken from Penn World Table 9.1. I choose $\delta=0.05$ to correspond to the standard annual rate (worldwide). The valueadded shares for each sector in each country, $\beta_{n}^{j}$, are calibrated using OECD STAN database, by calculating the ratio of value-added output to gross output in each sector. The input-output shares of each sector, $\gamma_{n}^{j}$, are also calibrated using the world input-output tables. Although the labor shares $\left(\alpha_{n}\right)$, value-added shares $\left(\beta_{n}^{j}\right)$, and input-output shares $\left(\gamma_{n}^{j}\right)$ change every year in the data, I fix them in the model and hold them to be time-invariant, taking the average of the values from 1992 to 2014.

There are two elasticities of substitution in the model. The first variable $\sigma$, which determines the elasticity of substitution between domestic and foreign merchandised goods, is set to match the short-run elasticity of substitution between goods in the standard international macroeconomic literature (elasticity of 1.5). For the elasticity of substitution between final tradable merchandised goods and final non-tradable services, I use $\eta=0.5$, taking this number from Johnson (2014).

\subsection{Paths of Capital}

Equipped with the initial parameters, I now discuss how I determine the paths of capital before backing out the shocks in the model. This procedure is critical in the larger accounting procedure, as I require shocks to satisfy the perfect foresight equilibrium path of the global economy. Here, I make a critical assumption: namely, that GDP, production of merchandised goods, consumption expenditure, labor hours, and bilateral trade shares from each country lie on the dynamic perfect foresight equilibrium path of the specified model.

With this assumption, I want the endogenous variables - such as GDP, production in merchandised goods, household consumption expenditure, labor hours, and bilateral trade shares - to follow the dynamics of the model. First, I assume that the shocks $\Psi_{t+1}$ remain unchanged after 2014, as we do not have any information on the global economy beyond the period covered in these data. In other words, the constant 
shocks can be described as

$$
\left\{\widehat{\Psi}_{t+1}\right\}_{2015}^{\infty}=1 \quad \text { and } \quad\left\{D_{n, t}^{S}\right\}_{2015}^{\infty}=D_{n, 2014}^{S}
$$

I am now ready to back out the path of capital. The world with constant shocks converges to the steady state in which all the endogenous variables do not change in magnitude. Given the data in 2014, I can compute the changes to capital, $\widehat{K}_{n, 2015}$, that lead the economy along the particular perfect foresight path to the steady state. ${ }^{20}$ Note that the Euler equation from the social planner's allocation is

$$
\frac{q_{n, t}}{\chi_{n, t}}=\rho\left[\frac{q_{n, t+1}}{\chi_{n, t+1}}(1-\delta)+r_{n, t+1}\right]
$$

By multiplying $\frac{\chi_{n, t}}{q_{n, t}}$ on both sides and using the definition that $X_{n, t}^{I} \equiv q_{n, t} I_{n, t}$, I can rewrite the Euler equation as

$$
1=\rho\left(\frac{\widehat{q}_{n, t+1}}{\widehat{\chi}_{n, t+1}}\right)(1-\delta)+\rho\left(\frac{r_{n, t+1} K_{n, t+1}}{X_{n, t}^{I}}\right)\left(1-(1-\delta) \widehat{K}_{n, t+1}^{-1}\right)
$$

The Euler equation (33) still requires knowledge of $\widehat{\chi}_{n, t+1}$, which is unknown at this point. To circumvent this problem, I incorporate the capital accumulation equation and combine it with the previous equation in order to obtain

$$
\frac{\widehat{K}_{n, t}}{\widehat{K}_{n, t}-(1-\delta)}=\rho\left(\frac{1-\delta}{\widehat{K}_{n, t+1}-(1-\delta)}\right) \widehat{X}_{n, t}^{I}+\rho\left(\frac{r_{n, t} K_{n, t}}{X_{n, t-1}^{I}}\right)
$$

The Euler equation (34) does not require any knowledge of shocks, as I have eliminated $\widehat{\chi}_{n, t+1}$. What is required to back out the path of capital, instead is the data on investment spending for each country, $X_{n, t}^{I}$, and $r_{n, t} K_{n, t}$. From the capital market clearing condition, we know that

$$
r_{n, t} K_{n, t}=(1-\alpha) Y_{n, t}
$$

Therefore, knowing GDP and investment spending is enough to deliver the path of capital that satisfies the perfect foresight equilibrium of this model.

\subsection{Paths of Shocks}

In this subsection, I discuss how I recover each set of shocks.

\footnotetext{
${ }^{20}$ This particular perfect foresight path rationalizes the data - GDP, production in merchandised goods, household consumption expenditure, labor hours, and bilateral trade shares.
} 


\subsubsection{TFP Shocks to Goods and Services}

TFP shocks to both the merchandised goods and services sectors can be directly calculated from combining the marginal costs of intermediate producers and market-clearing conditions. The equations to back out TFP shocks are

$$
\widehat{z}_{n, t+1}^{G}=\frac{\left[\left(\widehat{w}_{n, t+1}\right)^{\alpha_{n}}\left(\widehat{r}_{n, t+1}\right)^{1-\alpha_{n}}\right]^{\beta_{n}^{G}}\left[\left(\widehat{q}_{n, t+1}^{G}\right)^{\gamma_{n}^{G}}\left(\widehat{p}_{n, t+1}^{S}\right)^{1-\gamma_{n}^{G}}\right]^{1-\beta_{n}^{G}}}{\widehat{p}_{n, t+1}^{G}}
$$

and

$$
\widehat{z}_{n, t+1}^{S}=\frac{\left[\left(\widehat{w}_{n, t+1}\right)^{\alpha_{n}}\left(\widehat{r}_{n, t+1}\right)^{1-\alpha_{n}}\right]^{\beta_{n}^{S}}\left[\left(\widehat{p}_{n, t+1}^{S}\right)^{\gamma_{n}^{S}}\left(\widehat{q}_{n, t+1}^{G}\right)^{1-\gamma_{n}^{S}}\right]^{1-\beta_{n}^{S}}}{\widehat{p}_{n, t+1}^{S}}
$$

where $\widehat{p}_{n, t+1}^{G}$, is obtained by directly matching each country $n$ 's changes to producer price indices for merchandised goods (PPI), and where $\widehat{w}_{n, t+1}$ and $\widehat{r}_{n, t+1}$ are determined from the market- clearing conditions, using GDP, labor hours, and population data. ${ }^{21} \widehat{p}_{n, t+1}^{S}$ is an endogenous variable that is not matched with the data, and is solved in the equilibrium.

\subsubsection{Aggregate Demand Shocks}

Given that the planner's weights are time-invariant, the aggregate demand shock captures the fluctuations in a country's consumption spending. The equation that I use to back out the aggregate demand shocks is

$$
\widehat{\phi}_{n, t+1}=\widehat{q}_{n, t+1} \widehat{C}_{n, t+1} \equiv \widehat{X}_{n, t+1}^{C}
$$

where $\widehat{X}_{n, t+1}^{C}$ is defined as nominal consumption spending, in changes. I match $\widehat{C}_{n, t+1}$ with the real consumption expenditure of the households and the government from Penn World Table 9.1, so $\widehat{\phi}_{n, t+1}$ captures the volatility in which nominal consumption changes across time.

\subsubsection{Leisure Shocks}

Leisure shock comes from the marginal rate of substitution between consumption and leisure.

$$
\widehat{\xi}_{n, t+1}=\frac{\widehat{w}_{n, t+1}\left(1 \widehat{-l_{n, t+1}}\right) \widehat{N}_{n, t+1}}{\widehat{\phi}_{n, t+1}}
$$

\footnotetext{
${ }^{21} \mathrm{I}$ use changes to PPI as a proxy to match the changes to intermediate prices.
} 
To back out leisure shocks, it is crucial to match the average labor hours $l_{n, t}$ in order to calculate the changes to leisure itself, $1 \widehat{-l_{n, t+1}} . \widehat{N}_{n, t+1}$, population in changes, is exogenous and directly taken from the data. The changes to wages $\widehat{w}_{n, t+1}$ are determined from the labor market-clearing condition.

\subsubsection{Investment Shocks}

Investment shocks are backed out from the capital accumulation equation (9). Reformulating Equation (9), I obtain

$$
\chi_{n, t+1}=\frac{K_{n, t+2}-(1-\delta) K_{n, t+1}}{I_{n, t+1}} .
$$

Taking the ratio of $\chi_{n, t+1}$ and $\chi_{n, t}$, then the following expression for changes to investment shocks can be obtained

$$
\widehat{\chi}_{n, t+1}=\left(\frac{K_{n, t+2}-(1-\delta) K_{n, t+1}}{K_{n, t+1}-(1-\delta) K_{n, t}}\right) \frac{1}{\widehat{I}_{n, t+1}}
$$

and dividing by $\frac{K_{n, t+1}}{K_{n, t+1}}$ and using the definition $X_{n, t}^{I} \equiv q_{n, t} I_{n, t}$, the right-hand side can be re-written as

$$
\widehat{\chi}_{n, t+1}=\left(\frac{\widehat{K}_{n, t+2}-(1-\delta)}{1-(1-\delta) \widehat{K}_{n, t+1}^{-1}}\right) \frac{\widehat{q}_{n, t+1}}{\widehat{X}_{n, t+1}^{I}}=\left(\frac{\widehat{K}_{n, t+2}-(1-\delta)}{\widehat{K}_{n, t+1}-(1-\delta)}\right)\left(\frac{\widehat{q}_{n, t+1} \widehat{K}_{n, t+1}}{\widehat{X}_{n, t+1}^{I}}\right) .
$$

From the previous section, I already know the path of capital $\widehat{K}_{n, t+1}$. Furthermore, I match $\widehat{q}_{n, t+1}$ with changes to the Consumer Price Index (CPI) for each country $n$, which I interpret as the changes to final goods prices. Using the investment spending from the market clearing condition, I back out $\widehat{\chi}_{n, t+1}$. Note that investment shocks involve the $\widehat{K}_{n, t+2}$ term; investment shocks directly affect the social planner's intertemporal choices.

\subsubsection{Sectoral Shocks to Merchandised Goods Expenditures}

The sectoral shocks to merchandised goods expenditures affect the share of tradable merchandised goods. Changes in sectoral shocks to final goods expenditures, $\widehat{\theta}_{n, t+1}$, are backed out using the following relationship:

$$
\widehat{\theta}_{n, t+1}=\frac{\widehat{X}_{n, t+1}^{G}}{\widehat{X}_{n, t+1}}\left(\frac{\widehat{q}_{n, t+1}^{G}}{\widehat{q}_{n, t+1}}\right)^{\frac{\mu}{1-\mu}}
$$

where $\widehat{X}_{n, t+1}^{G}$ and $\widehat{X}_{n, t+1}$ are changes to the final absorption in merchandised goods and in total. $\widehat{q}_{n, t+1}^{G}$ and $\widehat{q}_{n, t+1}$ are changes in the price indices for tradable goods and final goods in total. I match the Consumer 
Price Index (CPI) with $q_{n, t}$, so the changes to the final good price index is equivalent to the changes in CPI for each country $n$.

\subsubsection{Trade-linkage Shocks}

To back out trade-linkage shocks, I start from changes to imported trade shares, $\widehat{\pi}_{n i, t+1}^{G}$, when $n \neq i$ and $n=i$ :

$$
\widehat{\pi}_{n i, t+1}^{G}=\left(\frac{\widehat{\operatorname{cost}}_{i, t+1}^{G} \widehat{d}_{n i, t+1}^{G}}{\widehat{z}_{i, t+1}^{G} \widehat{q}_{n, t+1}^{G}}\right)^{\frac{\sigma}{\sigma-1}} \quad \widehat{\pi}_{n n, t+1}^{G}=\left(\frac{\widehat{\operatorname{cost}}_{n, t+1}^{G} \widehat{d}_{n, t+1}^{G}}{\widehat{z}_{n, t+1}^{G} \widehat{q}_{n, t+1}^{G}}\right)^{\frac{\sigma}{\sigma-1}}
$$

Taking the ratio of these the above equations, and using the fact that $\widehat{p}_{n, t+1}^{G}=\frac{\widehat{\operatorname{cost}}_{n, t+1}^{G}}{\widehat{z}_{n, t+1}^{G}}$, I find that

$$
\left(\frac{\widehat{\pi}_{n i, t+1}^{G}}{\widehat{\pi}_{n n, t+1}^{G}}\right)^{\frac{\sigma-1}{\sigma}}=\left(\frac{\widehat{p}_{i, t+1}^{G}}{\widehat{p}_{n, t+1}^{G}}\right)\left(\frac{\widehat{d}_{n i, t+1}^{G}}{\widehat{d}_{n n, t+1}^{G}}\right)
$$

Furthermore, using the assumption that there is no cost in consuming your own goods $\left(d_{n i, t}^{G}=1\right.$ when $n=i)$, I back out the bilateral trade frictions from the following equation:

$$
\widehat{d}_{n i, t+1}^{G}=\left(\frac{\widehat{\pi}_{n i, t+1}^{G}}{\widehat{\pi}_{n n, t+1}^{G}}\right)^{\frac{\sigma-1}{\sigma}}\left(\frac{\widehat{p}_{n, t+1}^{G}}{\widehat{p}_{i, t+1}^{G}}\right)
$$

Using the data on bilateral trade volumes and producer price index (PPI), $\widehat{d}_{n i, t+1}^{G}$ can be directly backed out from matching the data.

\subsubsection{Population and Trade Deficit Shocks}

Population growth $\widehat{N}_{n, t+1}$ and trade deficits $D_{n, t}^{S}$ are directly taken from the data.

\subsection{Mechanism of How Each Set of Shocks Affects GDP Co-movement}

In this section, I discuss how each set of shocks can induce positive cross-country GDP co-movement. For the sake of simplicity, I consider a simple scenario in which there are only two countries (home and foreign), and I evaluate one set of shocks at a time, while keeping the other shocks constant. 


\subsubsection{TFP Shocks to Merchandised Goods}

Let's consider a simple scenario in which productivity for the merchandised goods sector increases for the home country, while the other shocks are unchanged. ${ }^{22}$ In such a case, the gross output for merchandised goods for the domestic market increases as home productivity increases. This induces the prices of merchandised goods, $p_{n, t}^{G}$, to fall and the terms of trade to depreciate, which makes the home country's merchandised goods more attractive for both domestically and abroad. Given Armington elasticity, foreign countries would demand more of home country's merchandised goods and would increase their imports from home country. Due to complementarity between imported home and foreign goods with given elasticities $\sigma$ and $\mu$, a foreign country increases its factor supplies and intermediate inputs to produce more of its own merchandised goods. This, in turn, increases the GDP of the foreign country, hence inducing the positive co-movement of both countries' GDP.

\subsubsection{Aggregate Demand Shocks}

Suppose there is a positive aggregate demand shock in the home country. The home country then increases its demand for both merchandised goods and for services. This demand would induce higher domestic output in gross production in merchandised goods and services, which requires more intermediate inputs. In turn, this causes an increase in the production of merchandised goods for foreign countries, which creates positive growth in outputs.

\subsubsection{Leisure Shocks}

Let us assume that there is a positive shock to leisure in the home country. This shock can be interpreted as meaning that people are "enjoying" more leisure, given that the wages and consumption levels are constant. In such a scenario, first of all, if people enjoy leisure more, then the real wages $w_{n, t}$ would increase, but labor supply would fall. ${ }^{23}$ With people working less, the factor supply would decrease overall, and output would decrease at home. Less output at home is linked to how much the country can export to foreign countries, as the price of the home traded goods rise, and the amount of exports decreases. Due to this complementarity between the home and foreign tradable sectors, then, the overall expenditure on the tradable sector decreases as the foreign output decreases - which leads to the co-movement of home and foreign GDP.

\subsubsection{Investment Shocks}

Let us now assume that there is an increase in investment shock, $\chi_{n, t}$, in the home country. As this shock determines investment efficiency, the return on investment, $I_{n, t}$, increases. This makes another unit of capital in $t+1$ to be more beneficial ( $K_{n, t+1}$ increases). Since the factor supply of capital tomorrow, $K_{n, t+1}$, increases, the cost per unit of capital or the final good price index, $q_{n, t+1}$, decreases. This leads to an increase in production within the intermediate and final goods sectors. The increase in intermediate sector production increase the output for the home country, which then increases exports to foreign countries. Furthermore, an increase in final goods sector production at home increases the amount of imported goods

\footnotetext{
${ }^{22}$ An increase in $z_{n, t}^{G}$.

${ }^{23}$ This can be interpreted as people working less. Since there is no unemployment in the model, it can appear as working less and "enjoying" more leisure.
} 
from foreign countries. The total effect leads to an increase in foreign output, thus leading to a positive output co-movement across countries.

\subsubsection{Sectoral Shocks}

To understand how the sectoral shocks work, suppose there is a positive shock to the tradable sector in country $n$ as $\theta_{n, t}$ increases. This gives a higher share of tradable merchandised goods compared to the nontradable service sector, and it induces more tradable goods to be made in country $n$, along with demanding more home and foreign intermediate merchandised goods from home and abroad. This creates positive output co-movement between the home and foreign country.

\subsubsection{Trade-linkage Shocks}

Here, I assume that all other shocks are constant, and only allow $d_{H F, t}$ to decrease (It is easier to trade between $H$ and $F$ ). This increases the amount of imported merchandised goods from a foreign country, which, in turn, increases the total expenditure on merchandised goods, both home and abroad $\left(X_{H, t}^{G}\right.$ and $X_{F, t}^{G}$ ). Moreover, since the demand for the merchandised goods has increased globally, each country increases its production of merchandised goods $\left(Y_{H, t}^{G}\right.$ and $\left.Y_{F, t}^{G}\right)$. Therefore, both home and foreign GDP $\left(Y_{H, t}\right.$ and $\left.Y_{F, t}\right)$ increase. ${ }^{24}$ How much impact trade-linkage shocks have ultimately depends on the elasticity of substitution, $\sigma$. If $\sigma<1$, both countries increase their output, which leads to positive GDP co-movement.

\subsection{Calibrated Shocks}

In this section, I discuss the calibrated shocks and show their correlations. Table 2 summarizes the correlations of the baseline shocks. Each row represents the average of all of the pair-wise correlations among the G7 countries and the ROW for the particular shock in question. Since I do not impose any correlation structures in the model, the pair-wise correlations among the countries are driven by the variations in the data.

I find that TFP shocks are the least correlated shocks across countries, particularly the TFP shocks to merchandised goods. ${ }^{25}$ On the other hand, sectoral shocks to final goods expenditure, as well as investment efficiency shocks are the most correlated among the G7 and ROW countries. However, the trade-linkage shocks are not as correlated as the other sets of shocks once I take the average of all the possible pairs among the countries. ${ }^{26}$

\subsection{Replicating the Data}

The set of shocks that I back out using the data, by definition, captures GDP and other macroeconomic aggregate variables for each country. In Table 3, I list the set of shocks and the data that I use to match with equations of the model, where I use 7 sequences of data to back out 7 sets of shocks from the model. Therefore, the model is exactly identified and the 7 sets of shocks completely describe the data.

\footnotetext{
${ }^{24}$ We can technically interpret trade-linkage shocks as bilateral technology shocks that home and foreign countries experience simultaneously.

${ }^{25}$ This is in line with the findings of Huo et al. (2020) where they find that utilization-adjusted TFP shocks are virtually uncorrelated.

${ }^{26}$ Furthermore, I calculate cross-shock correlations to make sure that there are no systematic correlations across shocks.
} 


\begin{tabular}{lc}
\hline Shock & Correlation (avg. of G7+ROW) \\
\hline$z_{n, t}^{G}$ (TFP to goods) & 0.1132 \\
$z_{n, t}^{S}$ (TFP to services) & 0.2872 \\
$\phi_{n, t}$ (Agg. demand) & 0.3624 \\
$\xi_{n, t}$ (Leisure) & 0.2125 \\
$\chi_{n, t}$ (Investment) & 0.4888 \\
$\theta_{n, t}$ (Sectoral) & 0.5028 \\
$d_{n i, t}$ (Trade-linkages) & 0.0142 \\
\hline
\end{tabular}

Table 2: Average of Cross-country Shock Correlations, 1992-2014

To check that this accounting procedure holds quantitatively, I perform a quantitative exercise wherein I feed into the model all the shocks that I obtained using the data and run a simulation. This simulation replicates the paths of GDP and other macroeconomic variables in levels and in changes exactly.

\begin{tabular}{lll}
\hline Shocks & Data & Source \\
\hline \hline TFP shock to merchandised goods $\left(z_{n, t}^{G}\right)$ & Gross production in merchandised goods $\left(Y_{n, t}^{G}\right)$ & OECD STAN \\
TFP shock to services $\left(z_{n, t}^{S}\right)$ & GDP $\left(Y_{n, t}\right)$ & PWT 9.1 \\
Aggregate demand shock $\left(\phi_{n, t}\right)$ & Consumption expenditure $\left(C_{n, t}\right)$ & PWT 9.1 \\
Leisure shock $\left(\xi_{n, t}\right)$ & Labor hours & PWT 9.1 \\
Investment shock $\left(\chi_{n, t}\right)$ & PPI in merchandised goods $\left(p_{n, t}^{G}\right)$ & OECD STAN \\
Sectoral shock $\left(\theta_{n, t}\right)$ & CPI $\left(q_{n, t}\right)$ & OECD STAN \\
Trade-linkage shock $\left(d_{n i, t}\right)$ & Bilateral trade imports $\left(X_{n i, t}\right)$ & OECD STAN \\
- & Population $\left(N_{n, t}\right)$ & PWT 9.1 \\
- & Services deficit $\left(D_{n, t}^{S}\right)$ & OECD STAN \\
\hline
\end{tabular}

Table 3: Data and Shocks

\subsection{Counterfactuals}

I now ask whether international trade (trade-linkage shocks) or correlated, country-specific shocks affect cross-country GDP co-movement. To answer this question, it is necessary to understand how the global economy would have evolved in a counterfactual world in which various shocks did not exist. Therefore, for each counterfactual scenario, I turn off one set of shocks at a time while keeping all other shocks on - or, in other words, I fix one shock to be constant at a time. These counterfactual analyses tell us how each country's macroeconomic variables would have evolved given each isolated set of counterfactual shocks. It is important, therefore, to discuss how counterfactual shocks arrive and how the social planner views them.

Any counterfactual shocks are unexpected by the social planner; when the social planner wakes up in the year 1992, she has already allocated all of the endogenous variables, such as GDP, consumption expenditure, changes to capital, and bilateral trade shares between countries, all based on the shocks that she has been 
expecting to come in 1993. If there are no changes to any of the shocks, then the social planner simply allocates the macroeconomic variables as they are observed in the data.

However, in a counterfactual world, a set of shocks changes in the middle of 1992, and the planner is caught by surprise, since she has already allocated each country's outcomes for 1992 and the future capital path between 1992 and 1993. Therefore, for 1993, the planner inefficiently allocates each country's GDP, consumption, and labor, and the amount of bilateral trade between countries. However, from 1993 onwards, she has already learned that the counterfactual shocks have arrived, and thus re-optimizes all the original allocations based on the new set of shocks starting from 1993 and onwards.

I take this approach because it is imperative that we know the initial levels of the model's endogenous outcomes, in order to start the algorithm. Hence, if a set of counterfactual shocks does not come as a surprise to the social planner, the initial outcomes of 1992 also cannot hold as they could not have been on the perfect foresight equilibrium path that she chose. In subsection E.1 of the Appendix, I describe how the social planner allocates endogenous outcomes in 1992 and 1993.

\section{Main Results}

In this section, I analyze how each set of shocks affects international business cycle synchronization from 1993 to 2014 (cross-country real GDP correlations) by running different counterfactual analyses. I focus on two counterfactuals in particular. In the first counterfactual scenario, I fix one shock to be constant at a time, while feeding the other shocks into the estimation; this is to understand how each shock individually affects the cross-country GDP co-movement when it is kept constant at initial-year levels (1992). A second set of counterfactuals, then, serves to shed light on multilateral transmission by fixing the trade-linkage shocks at initial-year levels for each country. Since the model outcomes produce counterfactual paths of real GDP in each country, any difference between the counterfactual cross-country GDP correlations and those from the data is the contribution of the set of shocks that has been fixed as constant.

\subsection{Contributions of Each Set of Shocks on Business Cycle Synchronization}

The main question of this paper aims to understand the primary driver(s) of international business cycle synchronization. With the shocks backed out in hand, I now answer the main question. Does international trade play a substantial role in synchronizing international business cycles, or are country-specific correlated shocks primarily responsible instead?

Table 4 summarizes the result. It shows the average of cross-country correlations of real GDP growth rates for every possible pair among the G7 countries and the rest of the world (ROW). The first row shows the real GDP correlation from the data, from 1993 to 2014. The average correlation from the data is 0.51, which shows that the business cycles among countries in the G7 and the rest of the world (ROW) are quite synchronized. Each of the other rows in the table shows the counterfactual correlations wherein each specified set of shocks is kept constant at initial year values and the remaining shocks are fed into the model.

From Table 4, I find that the trade-linkage shocks, $d_{n i, t}$, on average, affect the international business cycle synchronization the most, as the counterfactual GDP correlation yields the largest gap with the data correlation. Most of the country-specific correlated shocks play minimal roles, as the counterfactual GDP correlations are not very different from the actual data correlations. That said, sectoral shocks to tradable 
merchandise seem to be the second-most important type of shock. To understand these results in detail, I divide the data period into three waves as shown in the empirical section: 1993-1999 (the 1990s), 2000-2007 (the early 2000s), and 2008-2014 (The Great Recession and post recovery period).

\begin{tabular}{lc}
\hline Shocks & Avg. GDP Correlations \\
\hline Data & $\mathbf{0 . 5 1 0 8}$ \\
& \\
no $z_{n, t}^{G}$ (tradable TFP) & 0.4799 \\
no $z_{n, t}^{S}$ (services TFP) & 0.5436 \\
no $\phi_{n, t}$ (agg. demand shocks) & 0.6349 \\
no $\xi_{n, t}$ (leisure shocks) & 0.4473 \\
no $\chi_{n, t}$ (investment shocks) & 0.5213 \\
no $\theta_{n, t}$ (sectoral shocks to tradables) & 0.2339 \\
no $d_{n i, t}$ (trade-linkage shocks) & $\mathbf{0 . 1 3 5 8}$ \\
\hline
\end{tabular}

Table 4: Average Cross-country Correlations of Real GDP Growth Rates, 1993-2014

Table 5 shows the results for the three different waves. We observe that, on average, the international business cycles were not synchronized before 2000. After 2000, however, the cross-country GDP correlations jump to 0.58 , and the correlation rises even more after the Great Recession. We also calculate the counterfactual real GDP correlations for each period, and compare which sets of shocks were important.

I find that none of the shocks affect the cross-country GDP correlations significantly before 2000. If anything, productivity shocks to services and sectoral shocks would have synchronized cross-country business cycles more when those shocks were kept constant at their initial levels. The early-2000s, however, were very different from the 1990s; the global business cycles were much more positively synchronized in the later period. Comparing the counterfactual results, I find that the trade-linkage shocks are substantially more important than the other country-specific correlated shocks. Having kept the trade-linkage shocks constant, the cross-country real GDP correlations drop to 0.18 , which is approximately $70 \%$ drop from the real GDP correlations in the data. The Great Recession and the post-recovery period then synchronized the crosscountry business cycles even more. Trade-linkage shocks and sectoral shocks to final goods merchandise seemed to be the primary drivers of the GDP co-movement in this period.

Overall, these results tell us that shocks through international trade linkages have affected the global business cycle co-movement, and yet there are more intricate stories involved. For one, there has been a stark difference in global business cycle co-movement between the 1990s and the 2000s; trade-linkage shocks do not seem to matter all that much before 2000. In fact, productivity shocks to services appear to have hindered the global economy from synchronizing. However, once the early-2000s arrived, the world experienced a boom in international trade, accompanied by China's accession to the WTO. This large increase in international trade made countries more susceptible to trade shocks, and these expanded trade channels created a much higher degree of business cycle synchronization after 2000. Trade-linkage shocks were still important after the Great Recession and the post-recovery period, but the sectoral shocks to final goods merchandise became similarly important during this period. The emergence of the importance of sectoral 
shocks to the merchandised goods sector comes from an abnormal decline in manufacturing, particularly the manufacturing of durable goods, following the recession. Furthermore, the global economy faced an international trade collapse in 2009, which makes trade-linkage shocks one of the primary sources of business cycle synchronization in this period.

The main takeaways of the counterfactual analyses are, first, that trade-linkage shocks have been important in the increased degree of business cycle synchronization in the data. Second, the effects of the trade-linkage shocks have been dynamic as the global economy has become more economically integrated; concurrently, country-specific correlated shocks have become less important. These two results suggest that any policies that affect trade directly, such as trade agreements or tariff wars, will have a larger-than-ever impact on international business cycles, as the global economy has become more inter-connected through trade.

\begin{tabular}{lccc}
\hline Shocks & $1993-1999$ & $2000-2007$ & $2008-2014$ \\
\hline Data & $\mathbf{- 0 . 0 5 2 6}$ & $\mathbf{0 . 5 8 0 9}$ & $\mathbf{0 . 6 4 5 6}$ \\
& & & \\
no $z_{n, t}^{G}$ (tradable TFP) & -0.0480 & 0.7152 & 0.5917 \\
no $z_{n, t}^{S}$ (services TFP) & 0.1967 & 0.5045 & 0.7042 \\
no $\phi_{n, t}$ (agg. demand shocks) & -0.0323 & 0.6096 & 0.7926 \\
no $\xi_{n, t}$ (leisure shocks) & -0.0008 & 0.5557 & 0.5251 \\
no $\chi_{n, t}$ (investment shocks) & 0.0306 & 0.5506 & 0.5097 \\
no $\theta_{n, t}$ (sector shocks to tradables) & 0.1709 & 0.4334 & 0.1726 \\
no $d_{n i, t}$ (trade-linkage shocks) & 0.0548 & 0.1859 & 0.1283 \\
\hline
\end{tabular}

Table 5: Average Correlations of Real GDP Growth Rates, Three Time Waves
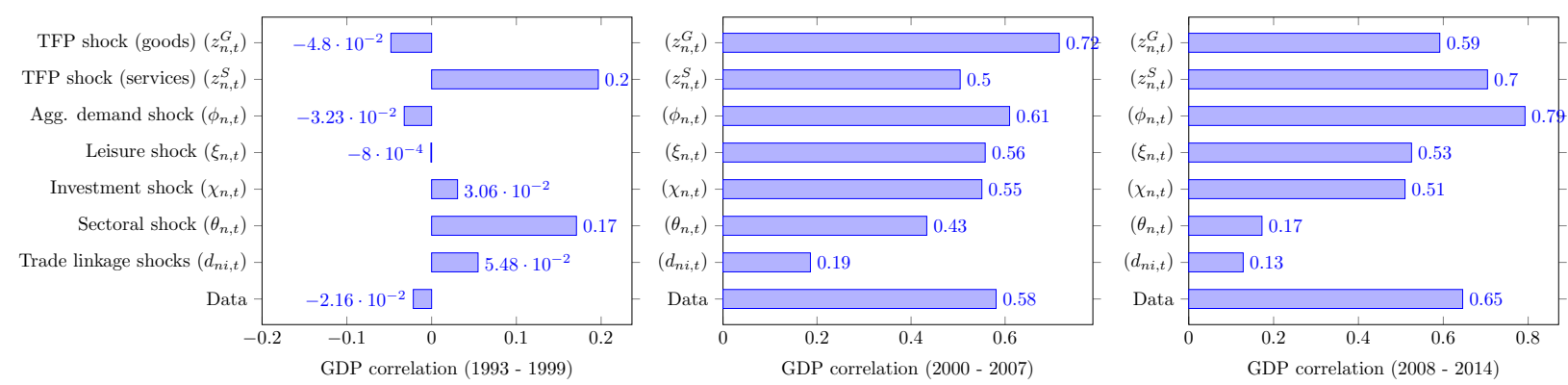

Figure 3: Average Correlations of Real GDP Growth Rates, Three Time Waves

\subsubsection{Results at the Country-Pair Level}

In this section, I delve deeper into the results and examine how each set of shocks affects the cross-country GDP co-movement for each country pair. Does the overall result that trade-linkage shocks are important carry over into individual country pairs as well? 
Table 6 shows the individual country-pair results. The left-most column that is denoted "all shocks" is the real GDP correlation between specified country pairs in the data. Columns on the right denote the country-pair real GDP correlations for each counterfactual scenario, in which the specified shock is fixed at constant 1992 levels. The correlations that are bolded are the counterfactual results that create the largest gap compared to the actual real GDP correlations in the data.

Among the G7 countries, I observe that holding trade-linkage shocks constant overwhelmingly yields the largest gap between the data and the counterfactual real GDP correlations. Even the country pairs in which trade-linkage shocks did not produce the largest counterfactual-versus-data gap, the trade-linkage shocks still had a non-negligible impact. The shocks that had the second-largest impact were the sectoral shocks to merchandised goods. Other country-specific shocks - such as TFP, demand, leisure, and investment shocks - had relatively minor roles in creating the co-movement between the country-pairs.

Overall, the effects of various shocks on the cross-country GDP co-movement are heterogeneous across country pairs. Nevertheless, trade-linkage shocks overwhelmingly had the largest impact on the GDP comovement for the majority of country-pairs.

\subsection{Which Country's Trade-Linkage Shocks Have the Largest Impact?}

Where are the trade-linkage shocks coming from? In this section, I run a series of counterfactuals in which I fix one country's trade-linkage shocks to remain constant at initial year levels (1992), while feeding in the rest of the trade-linkage shocks as well as the country-specific shocks.

Figure 4 presents the results from these decomposition counterfactuals. For illustration, take the first row of this plot, (CAN). This is a counterfactual in which trade-linkage shocks that do not involve Canada as origin or destination are at work, as well as country-specific shocks. The real GDP correlation from the data is 0.51 from 1993 to 2014 . When we fix the rest of the world (ROW) trade-linkage shocks, the counterfactual real GDP correlation decreases to 0.17 ; the set of ROW's trade-linkage shocks has the largest impact on the business cycle synchronization in the data.

The second-largest source of the trade-linkage shocks comes from the United States, followed by Germany. Trade-linkage shocks coming from Canada, by contrast, have the smallest impact, as the counterfactual GDP correlation - holding Canada's trade-linkage shocks constant at initial-year levels - is close to the data correlations. These results reveals more about the importance of trade in international business cycle synchronization; the larger a country's presence in the global trade market, the larger that country's impact on cross-country business cycle co-movement. Therefore, Figure 4 tells us that variations in common trade with the rest of the world synchronized international business cycles among the G7 countries, followed by the United States. It should be noted that the ROW data are mostly dominated by China; China's GDP and trade shares make up about $20 \%-25 \%$ of the ROW's GDP and imported trade shares. Furthermore, these results tell us more about the cross-border transmission of trade-linkage shocks; the impact of a common trading partner is important.

\subsection{Importance of Trade-linkage Shocks}

What are the trade-linkage shocks capturing in this dynamic model? In this section, I show in more detail why trade-linkage shocks are important, and what they capture in the data that standard international 


\begin{tabular}{|c|c|c|c|c|c|c|c|c|}
\hline \multirow[b]{2}{*}{ Country-pairs } & \multirow[b]{2}{*}{$\begin{array}{c}\text { All } \\
\text { shocks } \\
\text { (data) }\end{array}$} & \multicolumn{7}{|c|}{ Counterfactual Cross-country GDP Correlations (1993-2014) } \\
\hline & & $\begin{array}{c}\text { w/o merchandis } \\
\text { goods TFP } \\
\left(z_{n, t}^{G}\right)\end{array}$ & $\begin{array}{l}\text { o services } \\
\text { TFP } \\
\left(z_{n, t}^{S}\right)\end{array}$ & $\begin{array}{c}\text { w/o aggregate } \\
\text { demand shocks } \\
\left(\phi_{n, t}\right)\end{array}$ & $\begin{array}{c}\text { w/o leisure } \\
\text { shocks } \\
\left(\xi_{n, t}\right)\end{array}$ & $\begin{array}{l}\text { investm } \\
\text { shocks } \\
\left(\chi_{n, t}\right)\end{array}$ & $\begin{array}{c}\text { /o sectora } \\
\text { shocks } \\
\left(\theta_{n, t}\right)\end{array}$ & $\begin{array}{c}\text { w/o trade } \\
\text { shocks } \\
\left(d_{n i, t}\right)\end{array}$ \\
\hline US-Canada & 0.7644 & 0.8176 & 0.6799 & 0.8531 & 0.5198 & 0.6671 & 0.3517 & -0.0906 \\
\hline US-Germany & 0.7000 & 0.7104 & 0.5159 & 0.7427 & 0.6220 & 0.7908 & 0.4735 & 0.4214 \\
\hline US-France & 0.5991 & 0.6487 & 0.4825 & 0.6376 & 0.5066 & 0.7135 & 0.3718 & 0.6018 \\
\hline US-UK & 0.6749 & 0.6954 & 0.4004 & 0.7731 & 0.3659 & 0.6764 & -0.1875 & 0.5297 \\
\hline US-Italy & 0.6363 & 0.6749 & 0.5796 & 0.6330 & 0.3873 & 0.5496 & 0.4905 & 0.6155 \\
\hline US-Japan & 0.6135 & 0.2361 & 0.5984 & 0.7182 & 0.5440 & 0.5601 & 0.3540 & 0.6940 \\
\hline US-ROW & 0.0907 & 0.4254 & 0.5623 & 0.4965 & -0.0114 & 0.0156 & 0.0971 & -0.5616 \\
\hline Canada-Germany & 0.7645 & 0.6481 & 0.4270 & 0.7862 & 0.7069 & 0.8133 & 0.2645 & 0.1801 \\
\hline Canada-France & 0.4895 & 0.5187 & 0.4664 & 0.5847 & 0.4514 & 0.6247 & 0.2135 & -0.1525 \\
\hline Canada-UK & 0.6624 & 0.6363 & 0.5531 & 0.7451 & 0.5640 & 0.7441 & -0.1494 & 0.0028 \\
\hline Canada-Italy & 0.5152 & 0.5579 & 0.5494 & 0.6038 & 0.5204 & 0.5796 & 0.1818 & -0.2720 \\
\hline Canada-Japan & 0.5666 & 0.0809 & 0.5132 & 0.7372 & 0.4440 & 0.5611 & 0.1832 & -0.0744 \\
\hline Canada-ROW & 0.3745 & 0.4124 & 0.3300 & 0.5460 & 0.3348 & 0.1367 & -0.2833 & 0.1822 \\
\hline Germany-France & 0.7019 & 0.8908 & 0.8866 & 0.7203 & 0.7879 & 0.8198 & 0.8771 & 0.2649 \\
\hline Germany-UK & 0.5340 & 0.4656 & 0.3357 & 0.6846 & 0.4433 & 0.7793 & 0.0607 & -0.0013 \\
\hline Germany-Italy & 0.7579 & 0.6974 & 0.7887 & 0.8384 & 0.7439 & 0.7788 & 0.7348 & 0.0869 \\
\hline Germany-Japan & 0.4109 & 0.2315 & 0.6277 & 0.5185 & 0.5330 & 0.6038 & 0.3353 & 0.4132 \\
\hline Germany-ROW & 0.3423 & 0.3439 & 0.5656 & 0.4540 & 0.2926 & 0.1586 & 0.4356 & -0.1209 \\
\hline France-UK & 0.4820 & 0.5495 & 0.5190 & 0.6624 & 0.3994 & 0.6758 & 0.1325 & 0.5361 \\
\hline France-Italy & 0.7347 & 0.7763 & 0.8617 & 0.7968 & 0.6798 & 0.8063 & 0.6158 & 0.2861 \\
\hline France-Japan & 0.2571 & 0.2363 & 0.6448 & 0.3290 & 0.3849 & 0.4467 & 0.3765 & 0.6512 \\
\hline France-ROW & 0.2625 & 0.4224 & 0.6523 & 0.3744 & 0.1337 & 0.0616 & 0.5009 & -0.2499 \\
\hline UK-Italy & 0.5272 & 0.5942 & 0.5013 & 0.6531 & 0.3455 & 0.4671 & -0.1267 & 0.2594 \\
\hline UK-Japan & 0.7616 & 0.3087 & 0.2801 & 0.7587 & 0.7519 & 0.8094 & 0.1540 & 0.5803 \\
\hline UK-ROW & 0.1655 & 0.4005 & 0.3521 & 0.5295 & 0.1595 & 0.1005 & -0.1549 & -0.3285 \\
\hline Italy-Japan & 0.2714 & -0.0990 & 0.4372 & 0.4042 & 0.2925 & 0.1537 & -0.0411 & 0.1349 \\
\hline Italy-ROW & 0.2184 & 0.3979 & 0.6053 & 0.4155 & 0.2353 & 0.3474 & 0.4028 & -0.4229 \\
\hline Japan-ROW & 0.4238 & 0.1540 & 0.5046 & 0.7818 & 0.3852 & 0.1739 & 0.0054 & -0.3626 \\
\hline
\end{tabular}

Table 6: Largest Contributing Shocks for Each Country-pairs 


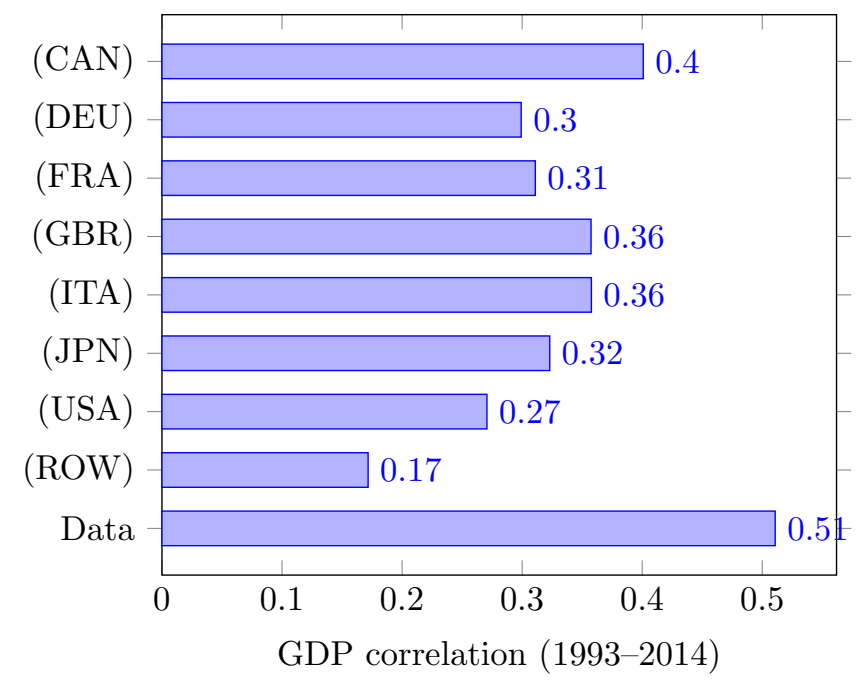

Figure 4: Decomposition of Trade-linkage Shocks

macroeconomic models fail to capture.

Figure 5 shows the importance of what happens when the trade-linkage shocks are fixed. The left panel of Figure 5 presents the evolution of domestic shares of merchandised goods for the United States, and the right one presents the evolution of domestic shares for Germany. For both countries, the blue line depicts data; the rest are counterfactual scenarios in which the specified shock is held constant while the other shocks are fed into the model.

In the data, we observe that the domestic shares of the United States declined from 0.84 to 0.7, and the decline for Germany was from 0.7 to 0.5. This tells us that there has been a significant decline in international trade barriers between the early-1990s and 2014. The global decline of trade barriers has been widely noted in previous studies, such as Santacreu and Zhu (2018).

When trade-linkage shocks are fixed, the counterfactual domestic shares show no significant decline compared to the data. However, the counterfactuals that involve correlated, country-specific shocks still exhibit a decline in domestic shares of merchandised goods for each country. This shows that the increase in economic integration due to trade is captured by the trade-linkage shocks in the model.

Digging deeper into the movements of trade-linkage shocks, I find that there are two components at work: a trend component and a cyclical component. The trend component of the trade-linkage shocks is what Figure 5 shows. Figure 6 , on the other hand, shows the cyclical component of the trade-linkage shocks, which captures the volatility of bilateral trade flows between countries. The blue lines in Figure 6 show the changes to imported trade shares in merchandised goods between selected country pairs. (USCanada and US-Germany). The bilateral import trade shares fluctuate quite significantly from 1992 to 2014. However, when the trade-linkage shocks are fixed, the trade shares do not fluctuate as much as the data, which is evident from the red lines in Figure 6. Without the fluctuations in trade-linkage shocks, then, the only potential source of fluctuations of bilateral trade flows is created by terms-of-trade shocks (through intermediate and final goods price indices). However, much of the literature - and first noted by Kehoe and Ruhl (2008) - has shown that the effects of terms-of-trade shocks are not very large when we consider 


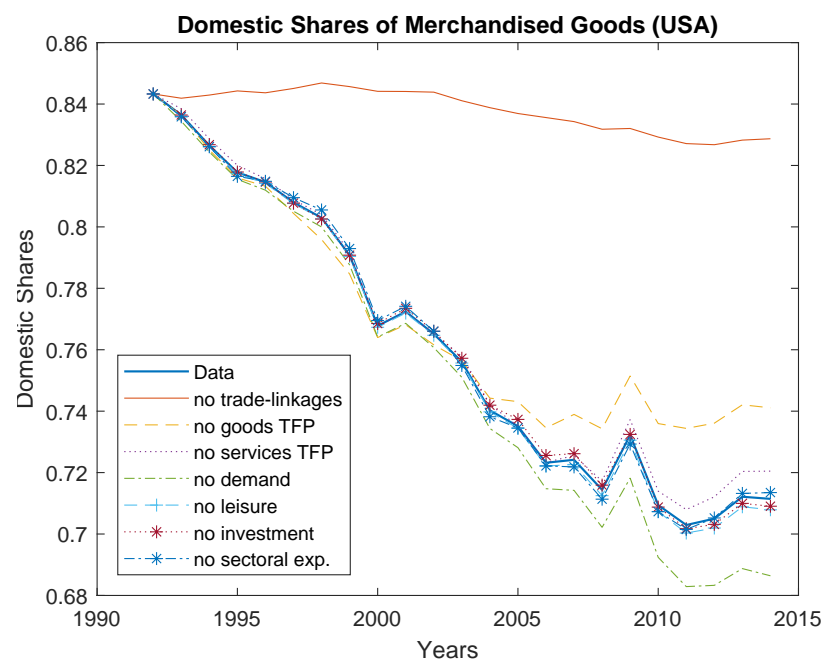

The United States

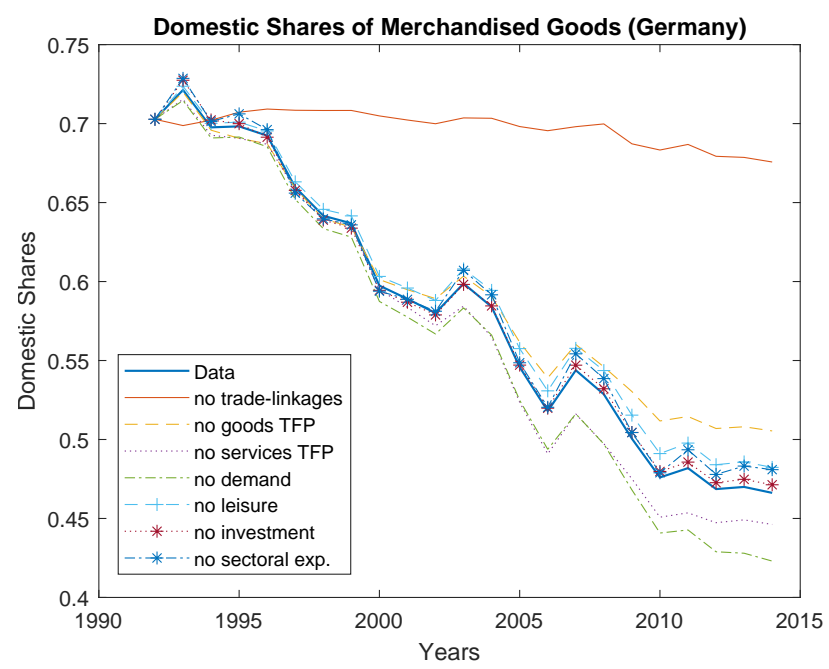

Germany

Figure 5: Domestic Shares of Merchandised Goods $\left(\pi_{n n, t}^{G}\right)$ : Data vs. Counterfactuals

cross-country GDP co-movement. ${ }^{27}$ This indeed is what we observe from Figure 6, where, accounting for the trade-linkage shocks that captures the trade flows from the data, there is more than the terms-of-trade shock effects on the GDP co-movement.

The intuition of the trade-linkage shocks that I capture in this paper is different from the previous literature. The traditional role of trade-linkages in the previous literature has been merely a shock propagation channel; one country's shock propagates to another country through trade linkages. Consider, for example, an increase in a given country's TFP; from there, the price of that country's exports to a given foreign country becomes cheaper. This improves home country's terms of trade because, as the foreign country imports more of home country's goods, the foreign GDP will rise, due to more imports from home country. These are the standard general equilibrium effects of shock propagation through trade that are commonly considered in previous literature. In the current paper, I have uncovered an additional, exogenous component that captures growth and fluctuations in international trade, as shown in Figure 5 and Figure 6, where none of the country-specific correlated shocks captures the decline in trade barriers and the volatility in trade flows between countries.

Overall, accounting for the trade-linkage shocks, which are modeled as iceberg costs, is important in understanding the global business cycle synchronization. The second implication of these counterfactual analyses is that increases in international trade also create higher GDP co-movement as countries are hit with trade shocks that are common to the paired countries simultaneously. This implication is in line with Frankel and Rose (1998), wherein higher trade does indeed synchronize international business cycles - a phenomenon captured by the trade-linkage shocks in the current paper. Therefore, understanding the relationship between trade and cross-country co-movement of business cycles is crucial in cross-country GDP co-movement.

\footnotetext{
${ }^{27}$ Kehoe and Ruhl (2008) show that foreign shocks through terms-of-trade effects do not have a lot of effect on home GDP.
} 

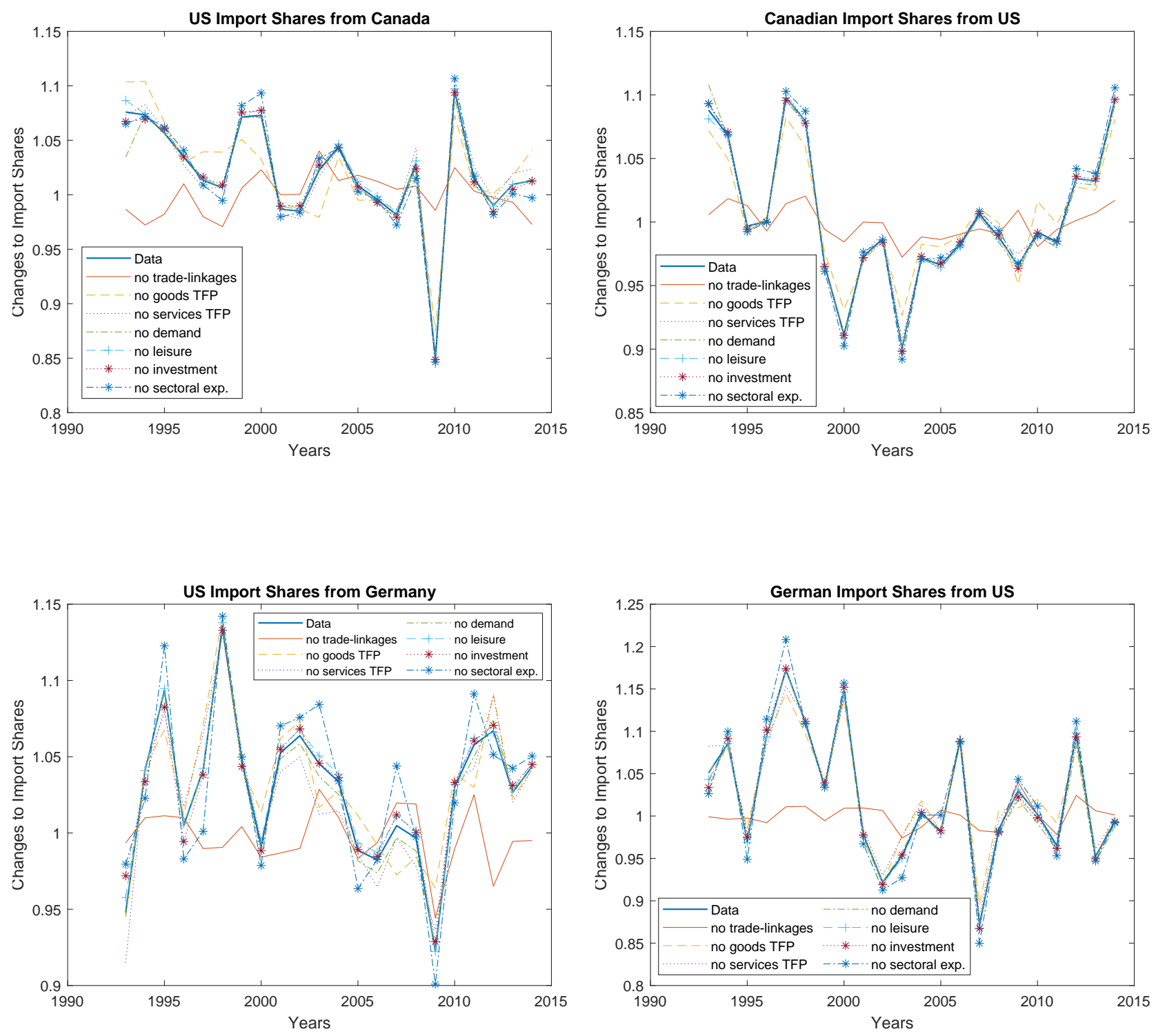

Figure 6: Changes to Trade Shares $\left(\widehat{\pi}_{n i, t}^{G}\right)$ : Data vs. Counterfactuals 
If this is necessary to understand, however, then why are standard international macroeconomic models are not able to capture the empirical relationship between trade and GDP co-movement (the trade co-movement puzzle)? Are the trade-linkage shocks also responsible for understanding this empirical relationship? In the next section, now, I analyze which shocks, in particular, are responsible for resolving the trade co-movement puzzle.

\section{Application: The Trade Co-movement Puzzle}

In this section, I analyze the trade co-movement puzzle proposed by Kose and Yi (2006), which considers the relationship between trade and cross-country business cycle co-movement. The trade co-movement puzzle is as follows: standard international real business cycle (IRBC) models do not generate the positive empirical relationship that is known to exist between trade and GDP co-movement in the data.

In my model, as noted in the previous section, trade-linkage shocks are the primary driver of international business cycle synchronization. So why do standard international macroeconomic models fail to generate this positive relationship between trade and GDP co-movement in the data? Since Kose and Yi (2006)'s seminal paper on the trade co-movement puzzle, there have been many attempts to solve this puzzle as many have proposed various solutions - yet we still do not have a clear, satisfying answer as to which mechanisms can account for the discrepancy between the data and the model counterpart. ${ }^{28}$

Are trade-linkage shocks ultimately responsible for the trade co-movement puzzle, or is it other countryspecific correlated shocks that we need to account for? To answer this question, I run the regression first proposed by Frankel and Rose (1998) and Kose and Yi (2006) with the counterfactual scenarios to understand which set of shocks are responsible.

Following Kose and Yi (2006), I estimate the following instrumental variables (IV) regression,

$$
\operatorname{corr}\left(\widetilde{G D P}_{i}, \widetilde{G D P}_{n}\right)=\beta_{0}+\beta_{1} \log \left(\text { Trade }_{i n}\right)+\varepsilon_{i n}
$$

where $\widetilde{G D P}_{i}$ represents the de-trended, first-difference growth rates of real GDP in country $i .{ }^{29} \log \left(\right.$ Trade $\left._{i n}\right)$, which is defined as bilateral trade intensity, is taken from Frankel and Rose (1998). The bilateral trade intensity is defined as

$$
\log \left(\text { Trade }_{i n}\right) \equiv \log \left(\frac{X_{i n}^{G}+X_{n i}^{G}}{G D P_{i}+G D P_{n}}\right)
$$

where $X_{j i}^{G}$ is defined as the value of imports that country $j$ receives from country $i .^{30}$ Instrumental variables for the regressions are the $\log$ of weighted distances between countries, a dummy variable for whether

\footnotetext{
${ }^{28}$ Burstein et al. (2008) introduce Leontiff production with global value chains, and Johnson (2014) extends IRBC model with input-output linkages, but both of these papers fail to generate the empirical relationship between trade and GDP co-movement. Liao and Santacreu (2015) and de Soyres and Gaillard (2019) argue that Melitz-type of model, with extensive margin of trade and love for variety, helps to resolve the puzzle. Drozd et al. (2019) argue that when trade elasticity varies across time, the puzzle is resolved.

${ }^{29} \operatorname{corr}\left(\widetilde{G D P}_{i}, \widetilde{G D P}_{n}\right)$ is the pairwise real GDP correlations that we observe in the data.

${ }^{30}$ This is a cross-sectional regression, as they are averaged over the time between 1992 and 2014
} 
a particular country pair shares a border, and a dummy for whether the country-pair shares a common language. ${ }^{31}$

\begin{tabular}{ccc}
\hline $\operatorname{corr}\left(\widetilde{G D P}_{i}, \widetilde{G D P}_{n}\right)$ & Kose \& Yi (2006) & Data (1992-2014) \\
\hline $\log \left(\right.$ trade $\left._{i n}\right)$ & $0.078^{* * *}$ & $0.072^{* * *}$ \\
& $(0.014)$ & $(0.015)$ \\
\hline Observations & 21 OECD & G7 \\
IV & Yes & Yes \\
\hline${ }^{* * *} p<0.01,{ }^{* *} p<0.05,{ }^{*} p<0.1$ &
\end{tabular}

Table 7: Kose \& Yi (2006) Regression

Table 7 compares the regression from Kose and Yi (2006) and the dataset that I use. The estimate that I obtain by running the instrumental variables (IV) regression is consistent with the literature. From Kose and Yi (2006), the slope coefficient for $\log \left(\right.$ Trade $\left._{i j}\right)$ is 0.078 , and their estimate comes from a study of 21 OECD countries from 1970 to 2000. The dataset that I use is composed of G7 countries from 1992 to 2014, and the estimated slope coefficient that I obtain is similar: 0.072 , with a standard error of 0.015 . This result confirms that my dataset still retains the empirical relationship that the previous literature finds.

Ever since Kose and Yi (2006)'s seminal paper, the goal in the trade co-movement puzzle literature has been to replicate this empirical relationship (slope coefficient) to see if how international macroeconomic models can capture this empirical phenomenon by introducing various mechanisms; the current section sheds light on which mechanism we need to replicate this relationship.

\begin{tabular}{|c|c|c|c|c|c|c|c|}
\hline $\operatorname{corr}\left(\widehat{G D P}_{i}, \widehat{G D P}_{n}\right)$ & $\begin{array}{c}\text { w/o goods } \\
\text { TFP }\end{array}$ & $\begin{array}{c}\text { w/o service } \\
\text { TFP }\end{array}$ & $\begin{array}{l}\text { agg. dem } \\
\text { shocks }\end{array}$ & $\begin{array}{c}\text { w/o leisur } \\
\text { shocks }\end{array}$ & $\begin{array}{l}\text { o investm } \\
\text { shocks }\end{array}$ & $\begin{array}{l}\text { /o sector } \\
\text { shocks }\end{array}$ & $\begin{array}{l}\mathrm{w} / \mathrm{o} \text { bilat. } \\
\text { trade shocks }\end{array}$ \\
\hline \multirow[t]{2}{*}{$\log \left(\right.$ Trade $\left._{i n}\right)$} & $0.207^{* * *}$ & $0.122^{* * *}$ & $0.062^{* * *}$ & $0.064^{* * *}$ & $0.075^{* * *}$ & $0.097^{*}$ & -0.066 \\
\hline & $(0.026)$ & $(0.03)$ & $(0.017)$ & $(0.028)$ & $(0.019)$ & $(0.05)$ & $(0.048)$ \\
\hline Observations & G7 & G7 & G7 & G7 & G7 & G7 & G7 \\
\hline IV & Yes & Yes & Yes & Yes & Yes & Yes & Yes \\
\hline
\end{tabular}

${ }^{* * *} p<0.01,{ }^{* *} p<0.05,{ }^{*} p<0.1$

Table 8: The Trade Co-movement Puzzle Counterfactuals

Table 8 shows the results of the regression estimates (47) with specified counterfactual scenarios. Each column in the table represents different counterfactual in which the specified shocks are kept constant at initial levels, while the other shocks are fed into the model as they are backed out from the data.

Several results stand out. First, without the trade-linkage shocks, the positive relationship between trade and cross-country GDP co-movement disappears. It is worthwhile to mention again that the trade-linkage shocks capture the growth of international trade (decline in trade barriers) and fluctuations in bilateral trade flows. As countries become more open to trade, countries' GDP becomes more responsive to factors

\footnotetext{
${ }^{31}$ The set of instrumental variables that I use here are the same as Frankel and Rose (1998) and Kose and Yi (2006).
} 
that create fluctuations in trade between countries, and this gradual openness to trade is captured by the trade-linkage shocks in this model. This is why, in standard IRBC models, GDP is not responsive to changes in trade, as these models do not allow for the exogenous trade-linkage shocks that hit both countries simultaneously; instead, they only account for the general equilibrium effects of shock propagation from one country to another. Therefore, when designing a model, in order to resolve the trade co-movement puzzle, it is crucial to incorporate mechanisms that can capture the dynamic patterns of trade.

Second, I find that none of the country-specific, correlated shocks is responsible for resolving the trade co-movement puzzle; furthermore, without TFP shocks to either merchandised goods or services, the relationship between trade and cross-country GDP co-movement becomes even larger. In fact, productivity shocks work in the opposite direction, dampening the relationship between trade and GDP co-movement. Apart from productivity shocks, though, the rest of the country-specific shocks - such as shocks to aggregate demand, leisure, investment, and final goods expenditure - do not have any discernible impact on the Frankel and Rose regression results.

These counterfactual results tell us more about the connection between the regression between two endogenous variables (47) and standard international macroeconomic models. We need to understand a set of deep, structural shocks that are driving this empirical result. The result tells us that the driving forces (components) in the model that are creating this empirical phenomenon come from the trade-linkage shocks.

\subsection{Connecting to the Trade Co-movement Puzzle Literature}

In this section, I discuss how my findings are linked to the current literature on the trade co-movement puzzle. How can we induce trade-linkage shocks that make countries' GDP more responsive? For this, I return to the imported trade-shares equation in the model.

$$
\pi_{n i, t}^{G}=\left(\frac{p_{i, t}^{G} d_{n i, t}^{G}}{q_{n, t}^{G}}\right)^{\frac{\sigma}{\sigma-1}}
$$

\subsubsection{Time-varying Armington Weights (Tariff and Non-tariff Trade Barriers)}

Trade-linkage shocks can be linked to tariffs, which do not fluctuate significantly every year in general. ${ }^{32}$ However, there are trade frictions involving non-tariff barriers that can appear as trade-linkage shocks in a model. What are the potential bilateral non-tariff barriers, in reality? They can take the form of import licensing, rules of origin, import-country-specific quotas, product quality standards, or anti-dumping laws. This is, by no means, an exhaustive list of non-tariff barriers to trade.

To show how tariff (or non-tariff) barriers can appear in a standard IRBC model, I now consider a model in which the composite production function for the tradable merchandised goods is

$$
T R_{n, t}^{G}=\sum_{i=1}^{N}\left(\omega_{n i, t}^{\sigma}\left(m_{n i, t}^{G}\right)^{\sigma}\right)^{\frac{1}{\sigma}}
$$

\footnotetext{
${ }^{32}$ This may not be true given the recent trade wars between various countries.
} 
This production function is different from the original model, as here I impose country-pair-specific weights $\omega_{n i, t}$ that vary across time. $\omega_{n n, t}$ can be interpreted as time-varying Armington weight that dictate a home-bias in intermediate goods. Using this production function, I can re-write the bilateral trade shares as

$$
\pi_{n i, t}^{G}=\left(\frac{\omega_{n i, t} p_{i, t}^{G} d_{n i, t}^{G}}{q_{n, t}^{G}}\right)^{\frac{\sigma}{\sigma-1}}=\left(\omega_{n i, t}\right)^{\frac{\sigma}{\sigma-1}}\left(\frac{p_{i, t}^{G} d_{n i, t}^{G}}{q_{n, t}^{G}}\right)^{\frac{\sigma}{\sigma-1}}
$$

By using data on tariff or non-tariff measures, these time-varying Armington weights can induce fluctuations in bilateral trade shares.

\subsubsection{Dynamic Trade Elasticity}

Another way in which a model can capture trade shocks is to allow for trade elasticities to vary across time; even though we do not usually calibrate trade elasticities to vary each period, we still perceive that they do indeed change across time in reality. In the main calibration, I set the trade elasticity $\frac{1}{1-\sigma}$ to be equal to 1.5 , which is a standard number between home and foreign goods in the international macroeconomics literature. However, standard international trade literature calibrates the trade elasticity to be much larger. ${ }^{33}$ Ruhl (2008) points out that measured elasticities can be different from one another when countries face temporary or permanent shocks.

Suppose that trade elasticity, $\sigma_{t}$, now has a subscript $t$ where it is allowed to be dynamic. Then from the original model, the composite merchandised goods production function now becomes

$$
T R_{n, t}^{G}=\sum_{i=1}^{N}\left(\left(m_{n i, t}^{G}\right)^{\sigma_{t}}\right)^{\frac{1}{\sigma_{t}}}
$$

where $\frac{1}{1-\sigma_{t}}$ is the dynamic trade elasticity. Using the new composite merchandised goods production function, bilateral trade shares can be written as

$$
\pi_{n i, t}^{G}=\left(\frac{p_{i, t}^{G} d_{n i, t}^{G}}{q_{n, t}^{G}}\right)^{\frac{\sigma_{t}}{\sigma_{t}-1}}
$$

The expression for the bilateral trade shares is similar to the original model in this paper, except for the expression for the trade elasticity which now is set to be time-varying. If the trade elasticity is dynamic, it makes the imported trade shares, $\pi_{n i, t}^{G}$, more volatile, which induces more shocks through GDP. On top of this, when the trade elasticity is dynamic, this also creates an additional channel that makes each country's GDP more susceptible to trade shocks.

Drozd et al. (2019) argue that dynamic trade elasticity is a potential source of solutions in the trade co-movement puzzle. In their paper, they introduce dynamic trade elasticity by incorporating a convex

\footnotetext{
${ }^{33}$ For example, Eaton and Kortum (2002) estimates the trade elasticities to be between 6 and 12 .
} 
adjustment cost on imported trade shares. The convex adjustment cost depends on the previous period's imported trade shares, which is paid in some portion of final goods.

\subsubsection{Extensive Margin Adjustments}

Another way in which we can capture trade-linkage shocks is by incorporating the extensive margin of trade, whereby we explicitly model the entry and exit of firms. There has been growing evidence that firms' entry and exit is an essential source of macroeconomic aggregate fluctuations. Hummels and Klenow (2005) finds that as countries are larger and richer, more exporting firms enter and exit the market. Using those findings, Liao and Santacreu (2015) and de Soyres and Gaillard (2019) go on to show that incorporating extensive trade margins in a monopolistic competitive model is a significant step toward solving the trade

co-movement puzzle. Here, I briefly discuss how the dynamic entry and exit decisions of exporting firms can create an additional channel for trade-linkage shocks in a model.

Suppose we have a monopolistic competitive economy à la Melitz. I can re-write the composite tradable goods production function as

$$
T R_{n, t}^{G}=\sum_{i=1}^{N}\left(\int_{\Omega_{i, t}}\left(m_{n i, t}^{G}(\omega)\right)^{\sigma} d \omega\right)^{\frac{1}{\sigma}}
$$

where $\Omega_{i, t}$ is defined to be a set of firms that are located in sourcing country $i$. Suppose, in equilibrium, that the number of firms that export from country $i$ at time $t$ is $M_{i, t}$. Then, the bilateral trade shares can be expressed as

$$
\pi_{n i, t}^{G}=\left(\frac{M_{i, t} \operatorname{cost}_{i, t}^{G} d_{n i, t}^{G}}{z_{i, t}^{G} q_{n, t}^{G}}\right)^{\frac{\sigma}{\sigma-1}}=\underbrace{\left(M_{i, t}\right)^{\frac{\sigma}{\sigma-1}}}_{\text {extensive margin }} \underbrace{\left(\frac{\operatorname{cost}_{i, t}^{G} d_{n i, t}^{G}}{z_{i, t}^{G} q_{n, t}^{G}}\right)^{\frac{\sigma}{\sigma-1}}}_{\text {intensive margin }}
$$

From Equation (55), the intensive margin component of imported trade shares is equivalent to the trade shares from this paper. However, there is an additional component where an extensive margin adjustment generates additional fluctuations in trade. This additional channel induces a country's GDP to be more responsive to changes to trade.

\section{Discussion on Trade-Linkage Shocks}

In this paper, trade-linkage shocks are modeled as standard iceberg costs, which can be interpreted as bilateral technology shocks that determine how efficiently goods are traded from one country to another. From the data, trade-linkage shocks capture the decline in international trade barriers and the fluctuations in bilateral trade flows between countries in merchandised goods (the primary and manufacturing sectors). What drives these fluctuations in bilateral trade flows in the data? I explore possible answers to this question by discussing potential exogenous sources. 


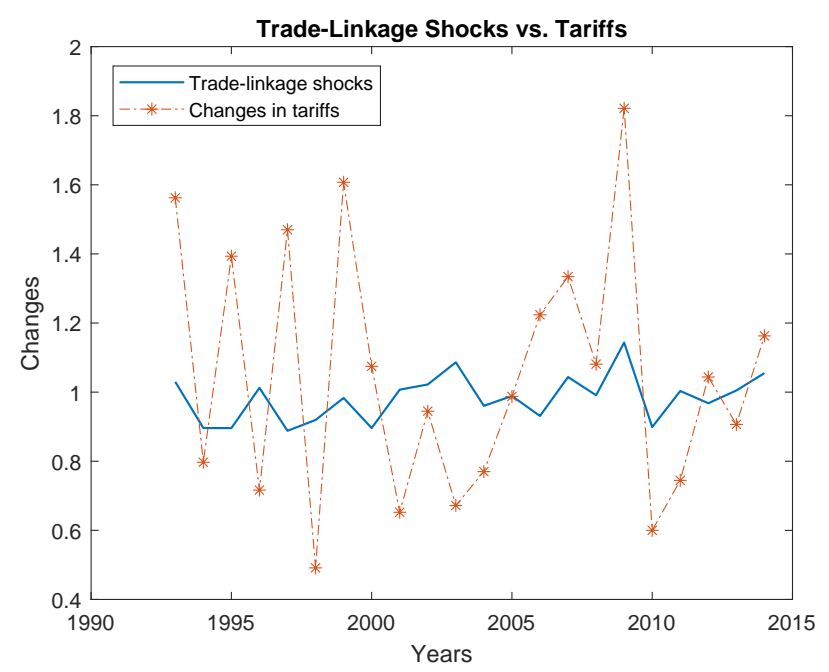

Trade-Linkage Shocks vs. Tariffs

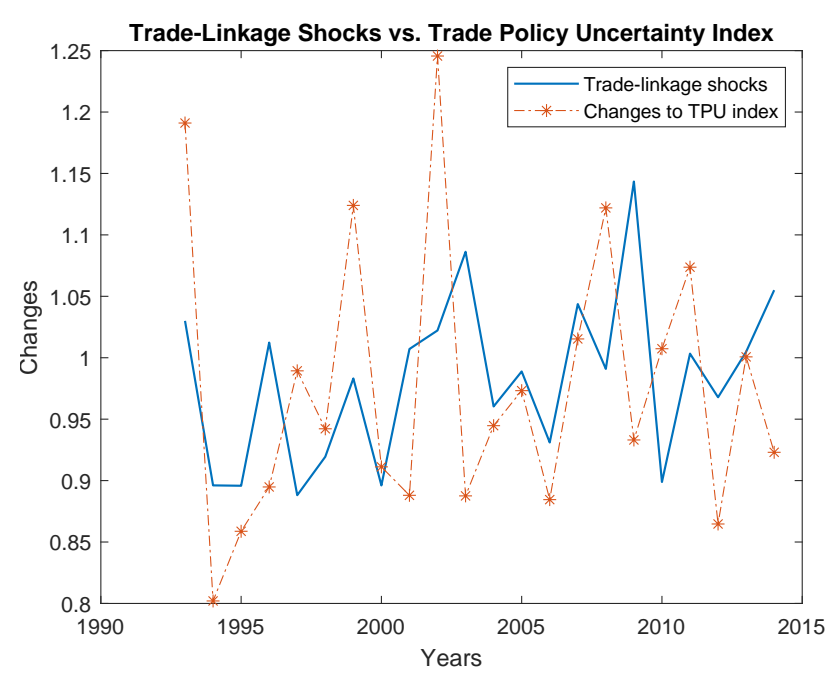

Trade-Linkage Shocks vs. TPU Index

Figure 7: Trade-Linkage Shocks with Exogenous Data

Tariffs and Non-Tariff Measures. One of the common explanations for the fluctuations in bilateral trade flows in the data is tariffs. The left panel of Figure 7 is a time-series comparison between changes to the average of the trade-linkage shocks across the countries and changes to tariffs. We observe that the correlations between the changes to tariffs and changes to trade-linkage shocks is 0.24 - a positive relationship. ${ }^{34}$ However, there are also non-tariff measures that may play a role in the volatility of trade flows; countries have used non-tariff measures to bypass tariff restrictions. Non-tariff measures include anti-dumping, countervailing, safeguard, rules-of-origin, and other preferential policy measures.

Firm Dynamics. There is a large literature on firm dynamics and trade, and how firm dynamics affect aggregate variables. The firm dynamics literature mostly focuses on disciplining models' structural parameters using micro data, but little is known about adding micro-foundations of firm dynamics to international macroeconomic models. Liao and Santacreu (2015) and de Soyres and Gaillard (2019) adapt monopolistic competition models to incorporate firms' extensive margin adjustments to understand the trade co-movement puzzle. Furthermore, inventory dynamics may have large effects on firm dynamics; Alessandria et al. (2013) and Alessandria et al. (2019) look at the macroeconomic impacts of the inventory stock adjustments that firms make when anticipating trade policy uncertainties. Firm dynamics (extensive margin adjustments) and inventory adjustments are likely to give fluctuations in bilateral trade flows in the data, and the findings of my paper indicate that trade-linkage shocks are crucial in understanding international business cycle synchronization. This tells us that we need to consider the micro-foundations of firm dynamics more seriously moving forward.

Trade Policy Uncertainties. Researchers and policymakers have also recently looked into how trade pol-

\footnotetext{
${ }^{34}$ I take the average of all of the trade-linkage shock pairs and construct the trade-linkage shock for the world.
} 
icy uncertanties might affect aggregate outcomes. The right panel of Figure 7 compares the average of the trade-linkage shocks that I back out and the changes to the trade policy uncertainty (TPU) index that was created by Caldara et al. (2020). The TPU index was constructed by counting the frequency of joint occurrences of trade policy uncertainty across major newspapers. ${ }^{35}$ The time-series comparison here shows that the trade-linkage shocks move similarly to the TPU index that was built exogenously. Furthermore, the correlation between the TPU index and the trade-linkage shocks from this paper is 0.24 .

Global Oil Prices. Another factor that might affect trade-linkage shocks is global oil prices. I take the global changes to oil prices from the Brent oil crude prices, and I measure the correlation between the calibrated trade-linkage shocks, averaged across the world. The correlation is negative $(-0.2695)$, so this tells us that the trade-linkage shocks have a counter-intuitive relationship with the crude oil prices.

There are other potential exogenous factors as well that affect fluctuations in bilateral trade flows between countries. Even though understanding the factors that contribute to the fluctuations of bilateral trade flows is outside of the scope of this paper, the main results of this paper still strongly indicate that the timevarying responses of trade to shocks have large implications in understanding international business cycles. Therefore, we must be cautious against calibrating models' trade shares to be fixed at steady-state import trade shares, as static international macro and trade models do. Instead, future researchers should focus on understanding better the influence that drive the dynamic evolutionary processes of trade flows between countries. ${ }^{36}$

\section{Conclusion}

In this paper, I highlight the effects of various shocks on cross-country business cycle synchronization. I find that cross-country GDP co-movement has been increasing for the past three decades due to trade-linkage shocks through increased economic integration, instead of country-specific correlated shocks. Furthermore, I show that without trade-linkage shocks, the model cannot capture the observed decline in domestic shares in merchandised goods nor the fluctuations in bilateral trade flows, even when other shocks are present. These findings show that the trade-linkage shocks that capture the growth and fluctuations in trade are large conduits that generate higher international business cycle co-movement.

Motivated by the findings that increased trade integration has synchronized international business cycles during the past three decades, I analyze the trade co-movement puzzle: standard international macroeconomic models are not able to capture the empirical relationship between trade and cross-country GDP co-movement. I find that incorporating trade-linkage shocks is essential in solving the trade co-movement puzzle. Trade-linkage shocks, which are manifested as iceberg trade costs in the model, create an additional exogenous channel whereby each country's GDP becomes more responsive when trade shares change. Therefore, I uncover that capturing the dynamics of trade patterns between countries is crucial in resolving the trade co-movement puzzle.

\footnotetext{
${ }^{35}$ The newspapers include The Boston Globe, Chicago Tribune, The Guardian, Los Angeles Times, The New York Times, The Wall Street Journal, and The Washington Post.

${ }^{36} \mathrm{~A}$ recent work by Alessandria et al. (2020) also points out that we must incorporate the trade adjustments that we observe in the data.
} 
Three assumptions in this paper can be relaxed for further analysis. First, by assuming perfect foresight, I limit the analysis to the structural shocks that are already known by the social planner. Allowing for stochasticity in the model can generate different estimated shocks that could result in different outcomes. Second, using other international trade models may result in a different set of shock decomposition to address movements in macro aggregates ${ }^{37}$ by comparing different classes of models, we can gain a more profound understanding of how shocks affect outcomes based on a variety of modeling assumptions. Third, relaxing the asset market completeness assumption can address the role of financial frictions in international business cycle co-movement, which can be helpful in disentangling the roles of economic and financial integration on international business cycle synchronization. I plan to address these issues in future research.

In conclusion, this paper's primary contribution is that understanding international business cycles relies on capturing the increased economic integration along with the volatility of trade-linkage shocks, which have not previously been studied together in depth in an open economy framework. Looking through the lens of this paper, in light of the rise of isolationistic policies and the ongoing backlash against globalization, we can expect that higher trade barriers and higher uncertainty in trade will both significantly affect international business cycles. Whether this paper's findings only apply to the past three decades or whether they also extend to the future is a question that will be answered as the global economy continues its cycles.

\footnotetext{
${ }^{37}$ Dynamic Eaton and Kortum (2002) or Ghironi and Melitz (2007) models can be used to back out shocks as well.
} 


\section{References}

Alessandria, G., J. Kaboski, and V. Midrigan (2013). Trade wedges, inventories, and international business cycles. Journal of Monetary Economics 60(1), 1-20.

Alessandria, G. A., C. Arkolakis, and K. J. Ruhl (2020). Firm dynamics and trade.

Alessandria, G. A., S. Y. Khan, and A. Khederlarian (2019). Taking stock of trade policy uncertainty: Evidence from chinas pre-wto accession.

Backus, D. K., P. J. Kehoe, and F. E. Kydland (1992). International real business cycles. Journal of political Economy 100(4), 745-775.

Baxter, M. and M. A. Kouparitsas (2005). Determinants of business cycle comovement: a robust analysis. Journal of Monetary Economics 52(1), 113-157.

Burstein, A., C. Kurz, and L. Tesar (2008). Trade, production sharing, and the international transmission of business cycles. Journal of Monetary Economics 55(4), 775-795.

Caldara, D., M. Iacoviello, P. Molligo, A. Prestipino, and A. Raffo (2020). The economic effects of trade policy uncertainty. Journal of Monetary Economics 109, 38-59.

Chari, V. V., P. J. Kehoe, and E. R. McGrattan (2007). Business cycle accounting. Econometrica 75(3), $781-836$.

de Soyres, F. and A. Gaillard (2019). Value added and productivity linkages across countries. Working paper.

Dekle, R., J. Eaton, and S. Kortum (2007). Unbalanced trade. American Economic Review 97(2), 351-355.

Drozd, L. A., S. Kolbin, and J. B. Nosal (2019). Long-run trade elasticity and the trade-comovement puzzle.

Eaton, J. and S. Kortum (2002). Technology, geography, and trade. Econometrica 70(5), 1741-1779.

Eaton, J., S. Kortum, B. Neiman, and J. Romalis (2016). Trade and the global recession. American Economic Review 106(11), 3401-3438.

Engel, C. and J. Wang (2011). International trade in durable goods: Understanding volatility, cyclicality, and elasticities. Journal of International Economics 83(1), 37-52.

Frankel, J. A. and A. K. Rose (1998). The endogenity of the optimum currency area criteria. The Economic Journal 108(449), 1009-1025.

Ghironi, F. and M. J. Melitz (2007). Trade flow dynamics with heterogeneous firms. American Economic Review 97(2), 356-361.

Greenwood, J., Z. Hercowitz, and G. W. Huffman (1988). Investment, capacity utilization, and the real business cycle. The American Economic Review, 402-417. 
Hummels, D. and P. J. Klenow (2005). The variety and quality of a nation's exports. American Economic Review 95(3), 704-723.

Huo, Z., A. A. Levchenko, and N. Pandalai-Nayar (2019). The global business cycle: measurement and transmission. Working paper.

Huo, Z., A. A. Levchenko, and N. Pandalai-Nayar (2020). Utilization-adjusted tfp across countries: Measurement and implications for international comovement.

Imbs, J. (2004). Trade, finance, specialization, and synchronization. Review of Economics and Statistics $86(3), 723-734$.

Johnson, R. C. (2014). Trade in intermediate inputs and business cycle comovement. American Economic Journal: Macroeconomics 6(4), 39-83.

Kehoe, T. J. and K. J. Ruhl (2008). Are shocks to the terms of trade shocks to productivity? Review of Economic Dynamics 11(4), 804-819.

Kose, M. A. and K.-M. Yi (2006). Can the standard international business cycle model explain the relation between trade and comovement? Journal of international Economics 68(2), 267-295.

Liao, W. and A. M. Santacreu (2015). The trade comovement puzzle and the margins of international trade. Journal of International Economics 96(2), 266-288.

Lucas, R. E. and E. C. Prescott (1971). Investment under uncertainty. Econometrica: Journal of the Econometric Society, 659-681.

Ohanian, L. E., P. Restrepo-Echavarria, and M. L. Wright (2018). Bad investments and missed opportunities? postwar capital flows to asia and latin america. American Economic Review 108(12), 3541-82.

Parkin, M. (1988). A method for determining whether parameters in aggregate models are structural. Carnegie-Rochester Conference Series on Public Policy 29, 215-252.

Raffo, A. (2010). Technology shocks: Novel implications for international business cycles.

Reyes-Heroles, R. (2017). The role of trade costs in the surge of trade imbalances. Working paper.

Ruhl, K. J. (2008). The international elasticity puzzle.

Santacreu, A. M. and H. Zhu (2018). Domestic innovation and international technology diffusion as sources of comparative advantage.

Stockman, A. C. and L. L. Tesar (1995). Tastes and technology in a two-country model of the business cycle: Explaining international comovements. The American Economic Review, 168-185. 
A Tables and Figures

\begin{tabular}{ll}
\hline Countries \\
\hline \hline Canada (CAN) \\
France (FRA) \\
Germany (DEU) \\
Italy (ITA) \\
United Kingdom (GBR) \\
United States (USA)) \\
Rest of the World (ROW) \\
\hline
\end{tabular}

Table 9: List of Countries 


\begin{tabular}{|c|c|c|c|c|}
\hline Country-pair & Code & 1992-1999 & 2000-2007 & 2008-2014 \\
\hline United States-Canada & USA-CAN & 0.3632 & 0.9234 & 0.8625 \\
\hline United States-Germany & USA-DEU & 0.4758 & 0.2176 & 0.8115 \\
\hline United States-France & USA-FRA & 0.7565 & 0.3030 & 0.6507 \\
\hline United States-United Kingdom & USA-GBR & -0.7827 & 0.7581 & 0.8135 \\
\hline United States-Italy & USA-ITA & 0.1342 & 0.3541 & 0.3937 \\
\hline United States-Japan & USA-JPN & -0.8217 & 0.9377 & 0.8585 \\
\hline United States-Rest of World & USA-ROW & -0.3597 & 0.5935 & 0.4088 \\
\hline Canada-Germany & CAN-DEU & 0.5178 & 0.2233 & 0.9361 \\
\hline Canada-France & CAN-FRA & 0.2403 & 0.3998 & 0.7304 \\
\hline Canada-United Kingdom & CAN-GBR & -0.1079 & 0.8035 & 0.8119 \\
\hline Canada-Italy & CAN-ITA & 0.1150 & 0.3515 & 0.7206 \\
\hline Canada-Japan & CAN-JPN & -0.2987 & 0.9745 & 0.6563 \\
\hline Canada-Rest of World & CAN-ROW & -0.0691 & 0.5682 & 0.6360 \\
\hline Germany-France & DEU-FRA & 0.7053 & 0.6298 & 0.8889 \\
\hline Germany-United Kingdom & DEU-GBR & -0.3038 & 0.1034 & 0.7440 \\
\hline Germany-Italy & DEU-ITA & 0.8238 & 0.8769 & 0.7086 \\
\hline Germany-Japan & DEU-JPN & -0.7891 & 0.3864 & 0.6460 \\
\hline Germany-Rest of World & DEU-ROW & -0.8837 & 0.8038 & 0.7214 \\
\hline France-United Kingdom & FRA-GBR & -0.3305 & 0.6035 & 0.7495 \\
\hline France-Italy & FRA-ITA & 0.6841 & 0.7109 & 0.5766 \\
\hline France-Japan & FRA-JPN & -0.9122 & 0.5021 & 0.6619 \\
\hline France-Rest of World & FRA-ROW & -0.6909 & 0.6788 & 0.7867 \\
\hline United Kingdom-Italy & GBR-ITA & 0.1115 & 0.3480 & 0.3878 \\
\hline United Kingdom-Japan & GBR-JPN & 0.6034 & 0.7822 & 0.8625 \\
\hline United Kingdom-Rest of World & GBR-ROW & 0.3136 & 0.4457 & 0.5322 \\
\hline Italy-Japan & ITA-JPN & -0.6222 & 0.5141 & 0.1487 \\
\hline Italy-Rest of World & ITA-ROW & -0.8947 & 0.7974 & 0.8577 \\
\hline Japan-Rest of World & JPN-ROW & 0.7836 & 0.6737 & 0.4139 \\
\hline Average & & -0.0526 & 0.5809 & 0.6456 \\
\hline
\end{tabular}

Table 10: GDP correlation: Data in three waves 


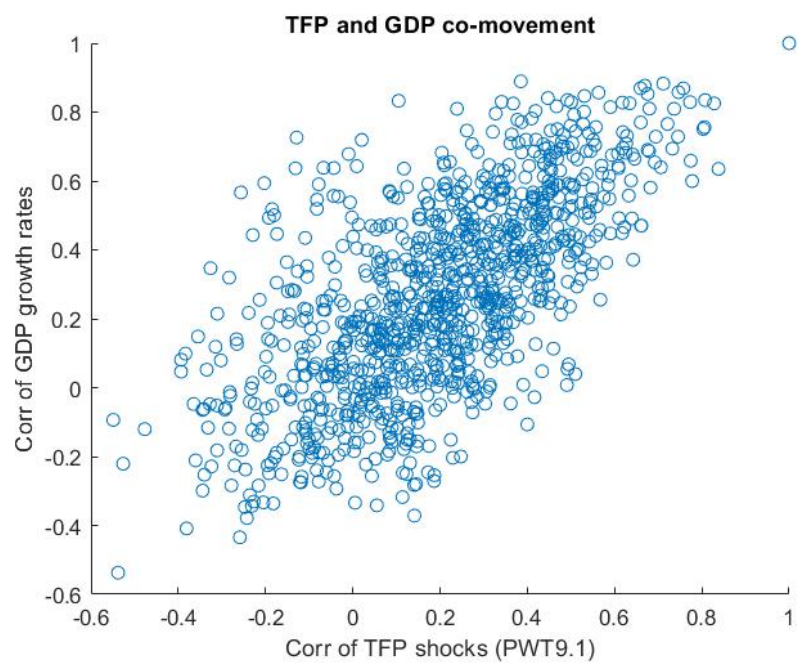

Correlation of GDP and TFP

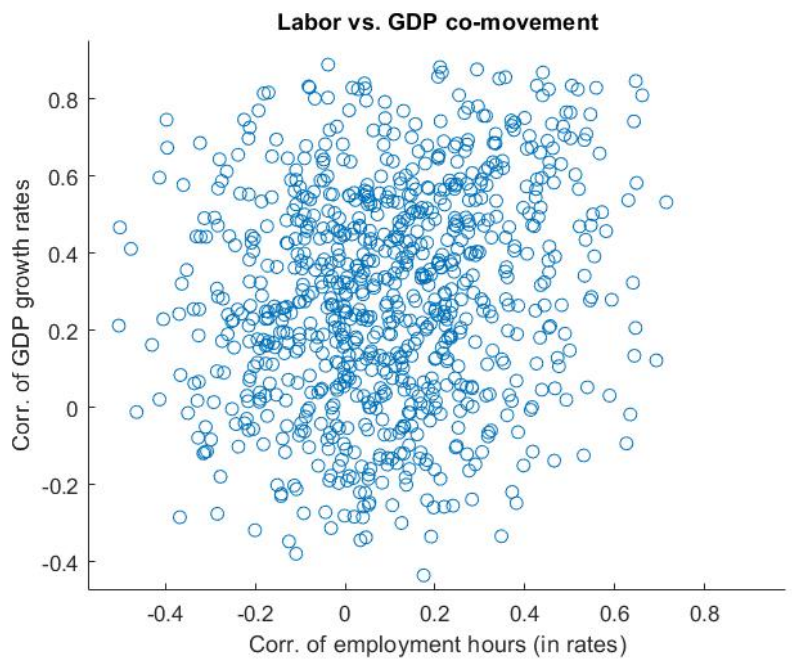

Correlation of GDP and Employment

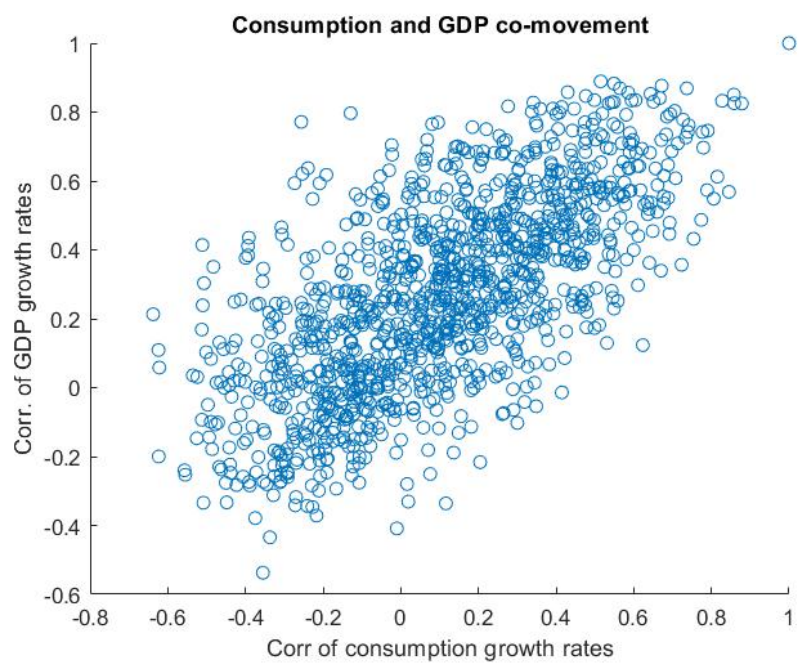

Correlation of GDP and Consumption

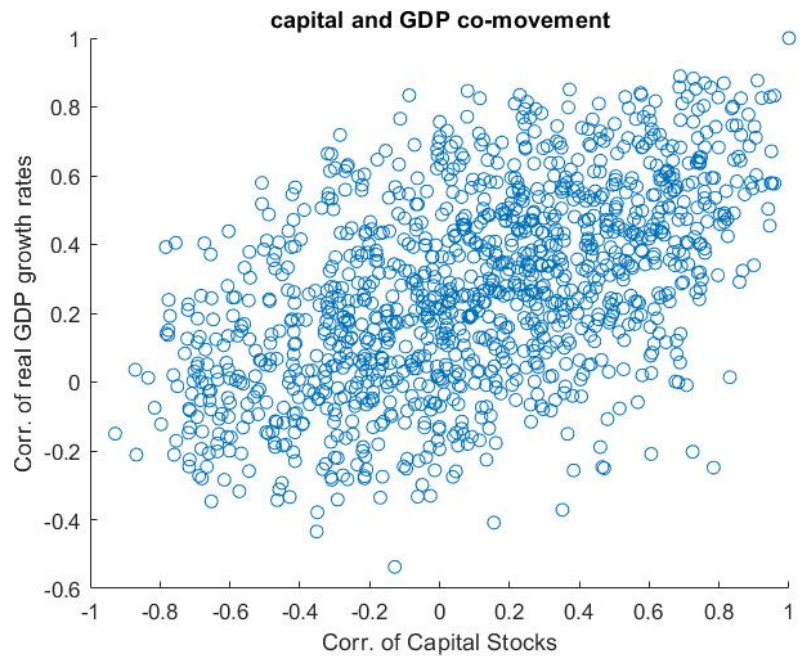

Correlation of GDP and Capital Stocks

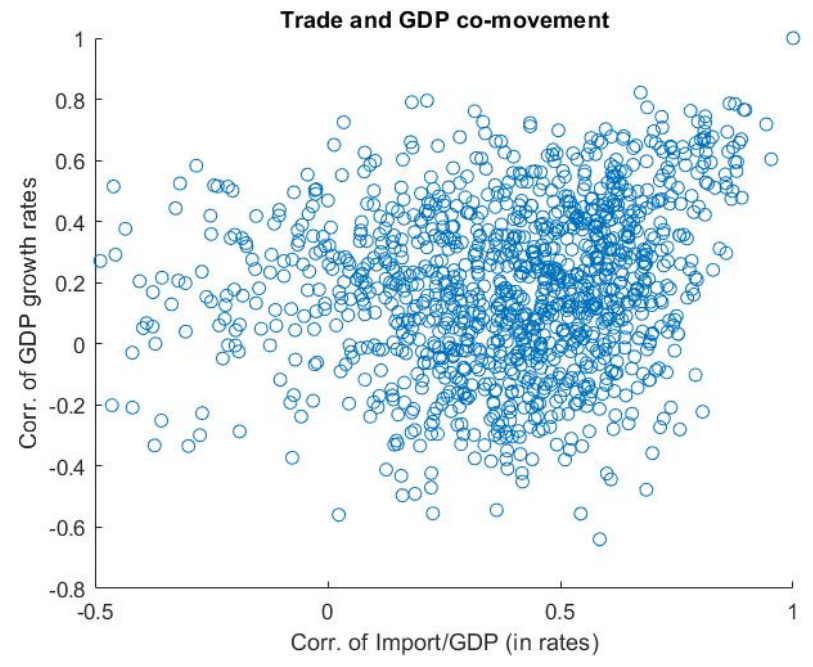

Correlation of GDP4and Total Imports

Figure 8: Cross-country Real GDP Correlations and Various Data 


\begin{tabular}{llll}
\hline Shocks & BENCHMARK, elasticity $=1.5$ & elasticity $=3$ & elasticity $=5$ \\
\hline \hline Data & $\mathbf{- 0 . 0 5 2 6}$ & $\mathbf{- 0 . 0 5 2 6}$ & $\mathbf{- 0 . 0 5 2 6}$ \\
& & & \\
no $z_{n, t}^{G}$ (tradable TFP) & -0.0480 & -0.0538 & -0.0338 \\
no $z_{n, t}^{S}$ (services TFP) & 0.1967 & 0.1797 & 0.1845 \\
no $\phi_{n, t}$ (agg. demand shock) & -0.0323 & -0.0137 & -0.0043 \\
no $\xi_{n, t}$ (leisure shock) & -0.0008 & -0.0002 & 0.0003 \\
no $\chi_{n, t}$ (investment shock) & 0.0306 & 0.0490 & 0.0430 \\
no $\theta_{n, t}$ (sector shock to tradables) & 0.1709 & 0.2342 & 0.2414 \\
no $d_{n i, t}$ (trade-linkage shocks) & 0.0548 & -0.0482 & -0.0467 \\
\hline
\end{tabular}

Table 11: Robustness for $\sigma$ : Correlations of real GDP growth rates, 1993-1999

\begin{tabular}{llll}
\hline Shocks & BENCHMARK, elasticity $=1.5$ & elasticity $=3$ & elasticity $=5$ \\
\hline \hline Data & $\mathbf{0 . 5 8 0 9}$ & $\mathbf{0 . 5 8 0 9}$ & $\mathbf{0 . 5 8 0 9}$ \\
& & & \\
no $z_{n, t}^{G}$ (tradable TFP) & 0.7152 & 0.6406 & 0.6365 \\
no $z_{n, t}^{S}$ (services TFP) & 0.5045 & 0.4846 & 0.4909 \\
no $\phi_{n, t}$ (agg. demand shock) & 0.6096 & 0.5452 & 0.5475 \\
no $\xi_{n, t}$ (leisure shock) & 0.5577 & 0.5666 & 0.5581 \\
no $\chi_{n, t}$ (investment shock) & 0.5506 & 0.5848 & 0.5758 \\
no $\theta_{n, t}$ (sector shock to tradables) & 0.4334 & 0.4706 & 0.4859 \\
no $d_{n i, t}$ (trade-linkage shocks) & $\mathbf{0 . 1 8 5 9}$ & $\mathbf{0 . 3 8 7 1}$ & $\mathbf{0 . 4 6 2 0}$ \\
\hline
\end{tabular}

Table 12: Robustness for $\sigma$ : Correlations of real GDP growth rates, 2000-2007

\begin{tabular}{llll}
\hline Shocks & BENCHMARK, elasticity $=1.5$ & elasticity $=3$ & elasticity $=5$ \\
\hline \hline Data & $\mathbf{0 . 6 4 5 6}$ & $\mathbf{0 . 6 4 5 6}$ & $\mathbf{0 . 6 4 5 6}$ \\
& & & \\
no $z_{n, t}^{G}$ (tradable TFP) & 0.5917 & 0.3367 & $\mathbf{0 . 2 6 8 3}$ \\
no $z_{n, t}^{S}$ (services TFP) & 0.7042 & 0.6462 & 0.6401 \\
no $\phi_{n, t}$ (agg. demand shock) & 0.7926 & 0.8046 & 0.8075 \\
no $\xi_{n, t}$ (leisure shock) & 0.5251 & 0.5308 & 0.5391 \\
no $\chi_{n, t}$ (investment shock) & 0.5097 & 0.5169 & 0.5173 \\
no $\theta_{n, t}$ (sector shock to tradables) & 0.1726 & 0.3126 & 0.3474 \\
no $d_{n i, t}$ (trade-linkage shocks) & $\mathbf{0 . 1 2 8 3}$ & $\mathbf{0 . 2 9 2 9}$ & 0.4821 \\
\hline
\end{tabular}

Table 13: Robustness for $\sigma$ : Correlations of real GDP growth rates, 2008-2014 


\begin{tabular}{llll}
\hline Shocks & $1993-1999$ & $2000-2007$ & $2008-2014$ \\
\hline \hline Data & $\mathbf{- 0 . 0 5 2 6}$ & $\mathbf{0 . 5 8 0 9}$ & $\mathbf{0 . 6 4 5 6}$ \\
& & & \\
no $z_{n, t}^{G}$ (tradable TFP) & 0.6058 & 0.7368 & 0.8325 \\
no $z_{n, t}^{S}$ (services TFP) & 0.3050 & 0.5944 & 0.6308 \\
no $\phi_{n, t}$ (agg. demand shock) & -0.0077 & 0.5854 & 0.7968 \\
no $\xi_{n, t}$ (leisure shock) & 0.1195 & 0.5665 & 0.5206 \\
no $\chi_{n, t}$ (investment shock) & 0.0337 & 0.5896 & 0.5152 \\
no $\theta_{n, t}$ (sector shock to tradables) & 0.1937 & 0.5616 & 0.7627 \\
no $d_{n i, t}$ (trade-linkage shocks) & 0.0117 & 0.1613 & 0.1625 \\
\hline
\end{tabular}

Table 14: Robustness for $\mu\left(\frac{1}{\mu-1}=0.5\right)$ : Correlations of real GDP growth rates 


\section{B Data Description}

My analysis includes G7 countries plus the Rest of World (ROW), across two sectors (traded merchandised goods and non-traded services). All macroeconomic variables are first matched in nominal terms, and then deflated by the United States GDP deflator. (US GDP deflator works as a numeraire.) All of the units are in terms of U.S. dollars in 2011 prices.

\section{B.1 GDP $\left(Y_{n, t}\right)$}

The most crucial data to match in this paper is the GDP of each country. Using Penn World Table 9.1, I match GDP at current PPP (purchasing power parity). Rest of the World (ROW) GDP is taken as the sum of the countries' GDP that are not part of G7.

\section{B.2 Gross Production in Merchandised Goods $\left(Y_{n, t}^{G}\right)$}

The annual gross production of merchandised goods are taken from OECD Structural Analysis Database (STAN), with ISIC Revision 4 categories. I define merchandised goods as the sum of three different sectors as noted in Table 15. To create the gross production for merchandised goods for each country, I obtain gross production for Agriculture, forestry and fishing, gross production for mining and quarrying, and gross production for manufacturing and add them to create total gross production of merchandised goods for each country.

\begin{tabular}{ll}
\hline Industries \\
\hline \hline Agriculture, Forestry \& Fishing (D01T03) \\
Mining \& Quarrying (D05T09) \\
Manufacturing (D10T33) \\
\hline
\end{tabular}

Table 15: Merchandised Goods

\section{B.2.1 Exchange Rates}

Gross production for merchandised goods are reported in countries' own currencies. To match the annual gross production values with GDP and bilateral trade data, I convert the production values using nominal exchange rates so that all gross production values for each country are in terms of U.S. dollars

\section{B.3 Labor hours $\left(l_{n, t}\right)$}

From Penn World Table 9.1, I take the average amount of hours worked for each country to match with the endogenous labor hours in the model. We know that one year consists of 8760 hours and I assume that people on average sleep 2920 hours per year, which amounts to 8 hours of sleep per day. Each representative consumer in country $n$ has to allocate 5840 hours either to work or to spend them on leisure. To have the data fit the model, I set 5840 hours to be the total amount of hours that each representative consumers in 
country $n$ are endowed with. Then, I match the endogenous labor choice, $l_{n, t}$, with the model such that

$$
l_{n, t} \equiv \frac{\text { avg. labor } \text { hours }_{n, t}}{5840}
$$

where average labor hours is taken directly from the data. Therefore, leisure, by definition, is equal to $1-l_{n, t}$ and the sum of the time available for workers in each country is normalized to 1 . For the rest of the world (ROW), I take the average of the remaining countries from Penn World Table 9.1 besides G7 countries.

\section{B.4 Consumption expenditure $\left(X_{n, t}^{C}\right)$}

I match nominal consumption of households and government, at current PPP (purchasing power parity) from Penn World Table 9.1. For the rest of the world (ROW) consumption expenditure, I take the sum of the rest of the countries in Penn World Table 9.1 excluding G7.

\section{B.5 Producer Price Index (PPI) $\left(p_{n, t}^{G}\right)$}

For intermediate good prices, I match them with domestic producer price index (PPI) in manufacturing. Producer Price Index for agriculture and Mining \& Quarrying sectors are not available, so I use manufacturing producer price index to match the intermediate price index. For the rest of the world (ROW), I use producer price index for total OECD countries from OECD Structural Analysis Database (STAN). The base year of PPI for each country from OECD STAN is 2015. To match with other macroeconomic aggregates, I convert each country's PPI to be in terms of 2011 base year.

\section{B.6 Consumer Price Index (CPI) $\left(q_{n, t}\right)$}

Consumer Price Indices (CPI) for each country are taken directly from OECD Structural Analysis Database (STAN). All of the countries have readily available CPI. For the rest of the world (ROW) CPI, I use average CPI for all of OECD countries. CPI is also deflated using 2011 as a base year.

\section{B.7 Bilateral Trade Shares $\left(\pi_{n i, t}\right)$}

\section{B.7.1 Total Bilateral Trade}

I take bilateral trade data from OECD Bilateral Trade by Industry and End-use ISIC Rev. 4, in annual levels. The total bilateral trade data are taken from the categories D01T99, and they are needed to calculate net exports and imports of each countries, and exogenous service deficits, which will be discussed in the next section.

\section{B.7.2 Merchandised Goods Bilateral Trade}

I divide the model into tradable (merchandised goods) and non-tradable (services) sectors. I take primary and manufactured goods bilateral trade data from 1992 to $2014 .^{38} \mathrm{I}$ take both bilateral exports and imports of primary and manufactured goods to calculate import shares for each bilateral country-pairs. I denote the

\footnotetext{
${ }^{38}$ This is categorized by (AM) in the data, and it includes Agriculture, Mining \& Quarrying, and Manufacturing industries (D01T32).
} 
amount of imports that country $n$ receives from country $i$ as $X_{n i, t}^{I M P, M}$, where the superscript $I M P$ represents "imports" and the superscript "G" represents merchandised tradable goods. Net exports of primary and manufactured goods are calculated using the total exports and imports of country $n$ :

$$
N X_{n, t}^{G}=X_{n, t}^{E X P, G}-X_{n, t}^{I M P, G}
$$

Equipped with data for gross production in merchandised goods $\left(Y_{n, t}^{G}\right)$, I can calculate total domestic absorption of tradable merchandised goods by

$$
X_{n, t}^{G}=Y_{n, t}^{G}-N X_{n, t}^{G}=Y_{n, t}^{G}-X_{n, t}^{E X P, G}+X_{n, t}^{I M P, G}
$$

which satisfies the global goods market clearing condition. To calculate bilateral import shares, I take the ratio between country $n$ 's imports from country $i$ over the total absorption (expenditure) of country $n$ :

$$
\pi_{n i, t}^{G}=\frac{X_{n i, t}^{I M P, G}}{X_{n, t}^{G}}
$$

To complete the bilateral trade share matrix, I need to calculate country $n$ 's own absorption, which is the gross production of merchandised goods that is consumed domestically. I denote this as $X_{n n, t}^{G}$.

$$
X_{n n, t}^{G}=Y_{n, t}^{G}-X_{n, t}^{E X P, G}
$$

Therefore, country $n$ 's own share is:

$$
\pi_{n n, t}^{G}=\frac{X_{n n, t}^{G}}{X_{n, t}^{G}}
$$

This allows us to have $\sum_{i=1}^{N} \pi_{n i, t}^{G}=1$.

\section{B.7.3 Rest of the World (ROW)}

Bilateral exports and imports for the rest of the world (RoW) are calculated in the following way. First, I assume that the rest of the world itself is a country, and no countries that consist of the rest of the world do not trade with each other. Suppose I want to calculate $X_{U S \leftarrow R O W, t}^{I M P, G}$, which is the amount of US imports from the rest of the world. I treat this as a residual from the total imports that the United States receive from the other G7 countries. Using the equation,

$$
X_{U S \leftarrow R O W, t}^{I M P, G}=X_{U S, t}^{I M P, G}-\sum_{i \neq R O W} X_{U S \leftarrow i, t}^{I M P, G}
$$

Using this formulation, the total exports that the rest of the world (RoW) make is:

$$
X_{R O W, t}^{E X P, G}=\sum_{n=1}^{N} X_{n \leftarrow R O W, t}^{I M P, G}
$$


On the other hand, I also need to know how much the rest of the world (RoW) import from each of the G7, which I define it as $X_{R O W \leftarrow i, t}^{I M P, G}$. Similarly, I treat this as a residual by subtracting the sum of country $i$ 's exports to G7, from the total exports of country $i$ :

$$
X_{R O W \leftarrow i, t}^{I M P, G}=X_{i, t}^{E X P, G}-\sum_{n \neq R O W} X_{n \leftarrow i, t}^{I M P, G}
$$

So the total imports by the rest of the world (ROW) is:

$$
X_{R O W, t}^{I M P, G}=\sum_{i=1}^{N} X_{R O W \leftarrow i, t}^{I M P, G}
$$

Using this method, I calculate the rest of the world's exports and imports for primary and manufacturing goods, $X_{R O W, t}^{E X P, G}$ and $X_{R O W, t}^{I M P, G}$ as well.

\section{B.8 Service Deficits}

I assume that the service sector is non-tradable in this paper. However, in reality, services are traded between countries. To avoid discrepancies in matching the data, I need to take into account for the services trade which does not appear in the model. For each country $n$, I use its GDP $\left(Y_{n, t}\right)$ and gross production in merchandised goods $\left(Y_{n, t}^{G}\right)$ to calculate gross production in services, using the GDP equation:

$$
Y_{n, t}^{S}=\frac{Y_{n, t}-\beta_{n}^{G} Y_{n, t}^{G}}{\beta_{n}^{S}}
$$

From total exports and imports between countries, I subtract bilateral exports and imports for merchandised goods:

$$
\begin{aligned}
& X_{n, t}^{E X P, S}=X_{n, t}^{E X P}-X_{n, t}^{E X P, G} \\
& X_{n, t}^{I M P, S}=X_{n, t}^{I M P}-X_{n, t}^{I M P, G}
\end{aligned}
$$

Since I do not allow for service sector to be traded, I take exports and imports of services as a residual to match the data. Therefore, I define service deficits as:

$$
D_{n, t}^{S} \equiv X_{n, t}^{E X P, S}-X_{n, t}^{I M P, S}
$$

which is treated as exogenous. I obtain domestic absorption (expenditure) of services sector by

$$
X_{n, t}^{S}=Y_{n, t}^{S}-D_{n, t}^{S}
$$




\section{Solving for Social Planner's Allocations}

I solve for the global social planner's problem in this section. The methodology listed out in this section is similar to Eaton et al. (2016). The global social planner's problem is:

$$
\begin{aligned}
\mathcal{L} & =\sum_{n=1}^{N} \sum_{t=0}^{\infty} \rho^{t}\left\{\omega_{n} \phi_{n, t}\left[\log \left(C_{n, t}\right)+\xi_{n, t} \log \left(N_{n, t} n_{n, t}\right)\right]+\right. \\
& +\lambda_{n, t}^{I N T, G}\left[z_{n, t}^{G}\left(\left(L_{n, t}^{G}\right)^{\alpha_{n}}\left(K_{n, t}^{G}\right)^{1-\alpha_{n}}\right)^{\beta_{n}^{G}}\left(\left(M_{n, t}^{G G}\right)^{\gamma_{n}^{G}}\left(M_{n, t}^{G S}\right)^{1-\gamma_{n}^{G}}\right)^{1-\beta_{n}^{G}}-y_{n, t}^{G}\right] \\
& +\lambda_{n, t}^{I N T, S}\left[z_{n, t}^{S}\left(\left(L_{n, t}^{S}\right)^{\alpha_{n}}\left(K_{n, t}^{S}\right)^{1-\alpha_{n}}\right)^{\beta_{n}^{S}}\left(\left(M_{n, t}^{S S}\right)^{\gamma_{n}^{S}}\left(M_{n, t}^{S G}\right)^{1-\gamma_{n}^{S}}\right)^{1-\beta_{n}^{S}}-y_{n, t}^{S}\right] \\
& +\lambda_{n, t}^{F G}\left[\left(\sum_{i=1}^{N}\left(m_{n i, t}^{G}\right)^{\sigma}\right)^{\frac{1}{\sigma}}-T R_{n, t}^{G}\right] \\
& +\lambda_{n, t}^{F}\left[\left(\left(\theta_{n, t}\right)^{1-\mu}\left(F_{n, t}^{G}\right)^{\mu}+\left(F_{n, t}^{S}\right)^{\mu}\right)^{\frac{1}{\mu}}-F_{n, t}\right] \\
& +\widetilde{\lambda}_{n, t}^{I N T}\left[y_{n, t}^{G}-\sum_{i=1}^{N} d_{i n, t}^{G} m_{i n, t}^{G}\right] \\
& +\lambda_{n, t}^{V}\left[(1-\delta) K_{n, t}+\chi_{n, t} I_{n, t}-K_{n, t+1}\right] \\
& +\lambda_{n, t}^{M C, F}\left[F_{n, t}-C_{n, t}-I_{n, t}\right] \\
& +\lambda_{n, t}^{M C, G}\left[T R_{n, t}^{G}-F_{n, t}^{G}-M_{n, t}^{G G}-M_{n, t}^{S G}\right] \\
& +\lambda_{n, t}^{M C, S}\left[y_{n, t}^{S}-F_{n, t}^{S}-M_{n, t}^{S S}-M_{n, t}^{G S}\right] \\
& \left.+\widetilde{\lambda}_{n, t}^{L}\left[N_{n, t}\left(1-\sum_{j \in\{G, S\}} \frac{L_{n, t}^{j}}{N_{n, t}}-n_{n, t}\right)\right]\right\}
\end{aligned}
$$

where each $\lambda$ is the Lagrangian multiplier associated with the corresponding constraint. The transversality condition is:

$$
\lim _{t \rightarrow \infty} \rho^{t} \lambda_{n, t}^{V} K_{n, t+1}=0
$$

for each country $n$.

Equipped with the Lagrangian equation (C.1), I can solve for all the allocations in the global economy that are equivalent to the perfect foresight competitive equilibrium. 


\section{C.1 Costs of (Tradable) Merchandised Goods and (Non-tradable) Services}

Primary inputs of the economy in each country are labor, capital, and intermediate inputs. In the subsections below, I take the first-order conditions for the each of the inputs in sector $j$.

\section{C.1.1 Costs of Labor}

I take the first-order condition with respect to labor $L_{n, t}^{j}$ for each sector $j \in\{G, S\}$ :

$$
\widetilde{\lambda}_{n, t}^{L}=\lambda_{n, t}^{I N T, j} z_{n, t}^{j}\left(\alpha_{n} \beta_{n}^{j}\right)\left(L_{n, t}^{j}\right)^{\alpha_{n} \beta_{n}^{j}-1}\left(K_{n, t}^{j}\right)^{\left(1-\alpha_{n}^{j}\right) \beta_{n}^{j}}\left[\left(M_{n, t}^{j j}\right)^{\gamma_{n}^{j}}\left(M_{n, t}^{j j^{\prime}}\right)^{1-\gamma_{n}^{j}}\right]^{1-\beta_{n}^{j}}
$$

Multiplying $L_{n, t}^{j}$ on both sides of (C.3) and collecting the terms on the right-hand side,

$$
\widetilde{\lambda}_{n, t}^{L}=\lambda_{n, t}^{I N T, j}\left(\alpha_{n} \beta_{n}^{j}\right) \frac{y_{n, t}^{j}}{L_{n, t}^{j}}
$$

The Lagrangian multiplier $\widetilde{\lambda}_{n, t}^{L}$ can be interpreted as wages for an individual worker in country $n$ at time $t$.

\section{C.1.2 Costs of Capital}

I take the first-order condition with respect to capital $K_{n, t}^{j}$ for each sector $j \operatorname{in}\{G, S\}$ :

$$
\widetilde{\lambda}_{n, t}^{K}=\lambda_{n, t}^{I N T, j} z_{n, t}^{j}\left(\left(1-\alpha_{n}^{j}\right) \beta_{n}^{j}\right)\left(L_{n, t}^{j}\right)^{\alpha_{n} \beta_{n}^{j}}\left(K_{n, t}^{j}\right)^{\left(1-\alpha_{n}^{j}\right) \beta_{n}^{j}-1}\left[\left(M_{n, t}^{j j}\right)^{\gamma_{n}^{j}}\left(M_{n, t}^{j j^{\prime}}\right)^{1-\gamma_{n}^{j}}\right]^{1-\beta_{n}^{j}}
$$

Multiplying $K_{n, t}^{j}$ on both sides of (C.5) and collecting the terms on the right-hand side,

$$
\tilde{\lambda}_{n, t}^{K}=\lambda_{n, t}^{I N T, j}\left(\left(1-\alpha_{n}\right) \beta_{n}^{j}\right) \frac{y_{n, t}^{j}}{K_{n, t}^{j}}
$$

The Lagrangian multiplier $\widetilde{\lambda}_{n, t}^{K}$ can be interpreted as rental rates of a unit of capital in country $n$ at time $t$.

\section{C.1.3 Costs of Intermediate Inputs}

I take the first-order condition with respect to the intermediate inputs $M_{n, t}^{j j}$ and $M_{n, t}^{j j^{\prime}}$ for each sector jin $\{G, S\}$ :

$$
\widetilde{\lambda}_{n, t}^{F, j}=\lambda_{n, t}^{I N T, j} z_{n, t}^{j}\left(\gamma_{n}^{j}\left(1-\beta_{n}^{j}\right)\right)\left[\left(L_{n, t}^{j}\right)^{\alpha_{n}}\left(K_{n, t}^{j}\right)^{1-\alpha_{n}^{j}}\right]^{\beta_{n}^{j}}\left(M_{n, t}^{j j}\right)^{\gamma_{n}^{j}\left(1-\beta_{n}^{j}\right)-1}\left(M_{n, t}^{j j^{\prime}}\right)^{\left(1-\gamma_{n}^{j}\right)\left(1-\beta_{n}^{j}\right)}
$$




$$
\widetilde{\lambda}_{n, t}^{F, j^{\prime}}=\lambda_{n, t}^{I N T, j} z_{n, t}^{j}\left(\left(1-\gamma_{n}^{j}\right)\left(1-\beta_{n}^{j}\right)\right)\left[\left(L_{n, t}^{j}\right)^{\alpha_{n}}\left(K_{n, t}^{j}\right)^{1-\alpha_{n}^{j}}\right]^{\beta_{n}^{j}}\left(M_{n, t}^{j j}\right)^{\gamma_{n}^{j}\left(1-\beta_{n}^{j}\right)}\left(M_{n, t}^{j j^{\prime}}\right)^{\left(1-\gamma_{n}^{j}\right)\left(1-\beta_{n}^{j}\right)-1}
$$

Multiplying $M_{n, t}^{j j}$ and $M_{n, t}^{j j^{\prime}}$ on both sides of (C.7) and (C.8), and collecting the terms on the right-hand side,

$$
\begin{gathered}
\widetilde{\lambda}_{n, t}^{F, j}=\lambda_{n, t}^{I N T, j}\left(\left(\gamma_{n}^{j}\right)\left(1-\beta_{n}^{j}\right)\right) \frac{y_{n, t}^{j}}{M_{n, t}^{j j}} \\
\widetilde{\lambda}_{n, t}^{F, j^{\prime}}=\lambda_{n, t}^{I N T, j}\left(\left(1-\gamma_{n}^{j}\right)\left(1-\beta_{n}^{j}\right)\right) \frac{y_{n, t}^{j}}{M_{n, t}^{j j^{\prime}}}
\end{gathered}
$$

\section{C.1.4 Calculating a Unit Cost Bundle}

We need to relate the shadow cost of producing a good to the shadow costs of the primary inputs (labor, capital, and other intermediate inputs). To do this, I define $Y_{n, t}^{j}$ as the value of the production of a good in country $n$ at time $t .{ }^{39}$

$$
Y_{n, t}^{j}=\lambda_{n, t}^{I N T, j} y_{n, t}^{j}=\lambda_{n, t}^{I N T, j} z_{n, t}^{j}\left(\left(L_{n, t}^{j}\right)^{\alpha_{n}}\left(K_{n, t}^{j}\right)^{1-\alpha_{n}}\right)^{\beta_{n}^{j}}\left(\left(M_{n, t}^{j j}\right)^{\gamma_{n}^{j}}\left(M_{n, t}^{j j^{\prime}}\right)^{1-\gamma_{n}^{j}}\right)^{1-\beta_{n}^{j}}
$$

Replacing $L_{n, t}^{j}, K_{n, t}^{j}, M_{n, t}^{j j}$, and $M_{n, t}^{j j^{\prime}}$ from using (C.4), (C.6), (C.9), and (C.10),

$$
Y_{n, t}^{j}=\lambda_{n, t}^{I N T, j} y_{n, t}^{j} \lambda_{n, t}^{I N T, j} z_{n, t}^{j}(\text { Cons })_{n}^{j}\left(\widetilde{\lambda}_{n, t}^{L}\right)^{-\alpha_{n} \beta_{n}^{j}}\left(\widetilde{\lambda}_{n, t}^{K}\right)^{-\left(1-\alpha_{n}\right) \beta_{n}^{j}}\left(\widetilde{\lambda}_{n, t}^{F, j}\right)^{-\gamma_{n}^{j}\left(1-\beta_{n}^{j}\right)}\left(\widetilde{\lambda}_{n, t}^{F, j^{\prime}}\right)^{-\left(1-\gamma_{n}^{j}\right)\left(1-\beta_{n}^{j}\right)}
$$

where $(\text { Cons })_{n}^{j}=\left(\alpha_{n} \beta_{n}^{j}\right)^{\alpha_{n} \beta_{n}^{j}}\left(\left(1-\alpha_{n}\right) \beta_{n}^{j}\right)^{\left(1-\alpha_{n}\right) \beta_{n}^{j}}\left(\gamma_{n}^{j}\left(1-\beta_{n}^{j}\right)\right)^{\gamma_{n}^{j}\left(1-\beta_{n}^{j}\right)}\left(\left(1-\gamma_{n}^{j}\right)\left(1-\beta_{n}^{j}\right)\right)^{\left(1-\gamma_{n}^{j}\right)\left(1-\beta_{n}^{j}\right)}$. Since $Y_{n, t}^{j}=\lambda_{n, t}^{I N T, j} y_{n, t}^{j}$, it is canceled out from both sides:

$$
1=\lambda_{n, t}^{I N T, j} z_{n, t}^{j}(\text { Cons })_{n}^{j}\left(\widetilde{\lambda}_{n, t}^{L}\right)^{-\alpha_{n} \beta_{n}^{j}}\left(\widetilde{\lambda}_{n, t}^{K}\right)^{-\left(1-\alpha_{n}\right) \beta_{n}^{j}}\left(\widetilde{\lambda}_{n, t}^{F, j}\right)^{-\gamma_{n}^{j}\left(1-\beta_{n}^{j}\right)}\left(\widetilde{\lambda}_{n, t}^{F, j^{\prime}}\right)^{-\left(1-\gamma_{n}^{j}\right)\left(1-\beta_{n}^{j}\right)}
$$

\footnotetext{
${ }^{39}$ This is matched with the gross production of merchandised goods from the data.
} 
Then, we can re-write the shadow price for a good $y_{n, t}^{j}$ as

$$
\lambda_{n, t}^{I N T, j}=\frac{(\text { Cons })_{n}^{j}\left[\left(\widetilde{\lambda}_{n, t}^{L}\right)^{\alpha_{n}}\left(\widetilde{\lambda}_{n, t}^{K}\right)^{1-\alpha_{n}}\right]^{\beta_{n}^{j}}\left[\left(\widetilde{\lambda}_{n, t}^{F, j}\right)^{\gamma_{n}^{j}}\left(\widetilde{\lambda}_{n, t}^{F, j^{\prime}}\right)^{1-\gamma_{n}^{j}}\right]^{1-\beta_{n}^{j}}}{z_{n, t}^{j}}
$$

Changing the notations as

$$
p_{n, t}^{j} \equiv \lambda_{n, t}^{I N T, j} \quad w_{n, t} \equiv \tilde{\lambda}_{n, t}^{L} \quad r_{n, t} \equiv \widetilde{\lambda}_{n, t}^{K} \quad \widetilde{\lambda}_{n, t}^{F, j} \equiv q_{n, t}^{F, j}
$$

We can re-write the above equation for goods and services:

$$
\begin{aligned}
p_{n, t}^{G}= & \frac{(\text { Cons })_{n}^{G}\left[\left(w_{n, t}\right)^{\alpha_{n}}\left(r_{n, t}\right)^{1-\alpha_{n}}\right]^{\beta_{n}^{G}}\left[\left(q_{n, t}^{G}\right)^{\gamma_{n}^{G}}\left(p_{n, t}^{S}\right)^{1-\gamma_{n}^{G}}\right]^{1-\beta_{n}^{G}}}{z_{n, t}^{G}} \\
p_{n, t}^{S} & =\frac{(\text { Cons })_{n}^{S}\left[\left(w_{n, t}\right)^{\alpha_{n}}\left(r_{n, t}\right)^{1-\alpha_{n}}\right]^{\beta_{n}^{S}}\left[\left(p_{n, t}^{S}\right)^{\gamma_{n}^{S}}\left(q_{n, t}^{G}\right)^{1-\gamma_{n}^{S}}\right]^{1-\beta_{n}^{S}}}{z_{n, t}^{S}}
\end{aligned}
$$

\section{C.2 Demand for Unit Merchandised (Tradable) Goods}

I take the first-order condition with respect to $y_{n, t}^{G}$. Then,

$$
\lambda_{n, t}^{I N T, G}=\tilde{\lambda}_{n, t}^{I N T}
$$

\section{C.3 Demand for Composite Merchandised (Tradable) Goods and Services}

I take the first-order conditions with respect to $F_{n, t}^{M}$ and $y_{n, t}^{S}$.

$$
\begin{gathered}
\lambda_{n, t}^{F G}=\lambda_{n, t}^{F}\left(F_{n, t}\right)^{1-\mu}\left(\theta_{n, t}\right)^{\mu-1}\left(F_{n, t}^{M}\right)^{\mu-1} \\
\lambda_{n, t}^{I N T, S}=\lambda_{n, t}^{F}\left(F_{n, t}\right)^{1-\mu}\left(y_{n, t}^{S}\right)^{\mu-1}
\end{gathered}
$$

Defining the Lagrangian prices as the following

$$
p_{n, t}^{S} \equiv \lambda_{n, t}^{I N T, S} \quad q_{n, t}^{G} \equiv \lambda_{n, t}^{F G} \quad q_{n, t} \equiv \lambda_{n, t}^{F}
$$

we can calculate final good price index by combining (C.15) and (C.16). 


\section{C.4 Merchandised Goods Trade}

In this subsection, I derive the bilateral imports demand for merchandised goods. I take the first-order condition with respect to $m_{n i, t}$.

$$
\tilde{\lambda}_{i, t}^{I N T} d_{n i, t}=\lambda_{n, t}^{F G}\left(F_{n, t}^{G}\right)^{\frac{1-\sigma}{\sigma}}\left(m_{n i, t}\right)^{\sigma-1}
$$

Since $\widetilde{\lambda}_{n, t}^{I N T}=\lambda_{n, t}^{I N T, G}$, we can re-write the previous equation as

$$
p_{i, t} d_{n i, t}=q_{n, t}^{G}\left(F_{n, t}^{G}\right)^{\frac{1-\sigma}{\sigma}}\left(m_{n i, t}\right)^{\sigma-1}
$$

Using this equation, we can obtain composite merchandised goods price index $q_{n, t}^{G}$.

\section{C.5 Demand for Final Goods}

Taking the first-order condition with respect to $F_{n, t}$, we get

$$
\lambda_{n, t}^{F}=\lambda_{n, t}^{M C}
$$

and this tells us that both of these prices are equal to the final good price index, and I define it as $q_{n, t}$.

\section{C.6 Consumption}

I take the first-order condition with respect to $c_{n, t}$ :

$$
\widetilde{\lambda}_{n, t}^{C} C_{n, t}=\omega_{n} \phi_{n, t}
$$

Letting $q_{n, t} \equiv \widetilde{\lambda}_{n, t}^{C}$, we can re-write this as:

$$
q_{n, t} c_{n, t}=\frac{\omega_{n} \phi_{n, t}}{N_{n, t}}
$$

\section{C.7 Leisure}

I derive the marginal rate of substitution between consumption and leisure. I take the first-order condition with respect to $n_{n, t}$, which is equal to $1-l_{n, t}$.

$$
\widetilde{\lambda}_{n, t}^{L} N_{n, t}=\omega_{n} \phi_{n, t} \xi_{n, t} \frac{1}{1-l_{n, t}}
$$

Replacing $w_{n, t} \equiv \widetilde{\lambda}_{n, t}^{L}$, we have

$$
w_{n, t}\left(1-l_{n, t}\right) N_{n, t}=\omega_{n} \phi_{n, t} \xi_{n, t}
$$




\section{C.8 Investment}

In this subsection, I derive the Euler equation of the model. First, I take the first-order condition with respect to $I_{n, t}$ :

$$
\lambda_{n, t}^{M C}=\lambda_{n, t}^{V} \chi_{n, t}
$$

Now we take the first-order condition with respect to $K_{n, t+1}$ :

$$
\lambda_{n, t}^{V}=\rho \lambda_{n, t+1}^{V}(1-\delta)+\rho \widetilde{\lambda}_{n, t+1}^{K}
$$

Using equation (C.16), I can replace $\lambda_{n, t}^{V}$ and $\lambda_{n, t+1}^{V}$.

$$
\frac{\lambda_{n, t}^{M C}}{\chi_{n, t}}=\rho\left[\frac{\lambda_{n, t+1}^{M C}}{\chi_{n, t+1}}(1-\delta)+\widetilde{\lambda}_{n, t+1}^{K}\right]
$$

Letting

$$
q_{n, t} \equiv \lambda_{n, t}^{M C} \quad \widetilde{\lambda}_{n, t}^{K} \equiv r_{n, t}
$$

I obtain the Euler equation from the model.

$$
\frac{q_{n, t}}{\chi_{n, t}}=\rho\left[\frac{q_{n, t+1}}{\chi_{n, t+1}}(1-\delta)+r_{n, t+1}\right]
$$




\section{Model Calculation (Details)}

In this section, I show how I calculate the model, given the initial parameters and exogenous shocks. I follow the hat-algebra method by Dekle et al. (2007) to solve the model exactly. By solving the model exactly, it is possible to express all the shocks and the endogenous outcomes of the model in changes.

\section{D.1 Initial Parameters and Exogenous Shocks}

There are initial parameters that are time-invariant, which I denote as $\Omega$.

$$
\Omega=\left\{\alpha_{n}, \beta_{n}^{j}, \gamma_{n}^{j}, \sigma, \rho, \mu, \beta\right\}
$$

I denote time-varying shocks to be $\widehat{\Psi}_{t+1}$.

$$
\Psi_{t}=\left\{z_{n, t}^{G}, z_{n, t}^{S}, \phi_{n, t}, \xi_{n, t}, \chi_{n, t}, \theta_{n, t}, d_{n i, t}^{G}, N_{n, t}, D_{n, t}^{S}\right\}
$$

Using the set of time-invariant initial parameters $\Omega$ and the set of time-varying structural shocks $\Psi_{t}$, I show the algorithm to calculate the endogenous outcomes of the equilibrium.

\section{D.2 Calculating Endogenous Outcomes of the Model}

Equipped with the initial parameters and structural shocks, the paths of endogenous outcomes of the model can be calculated. Let's say that the initial period starts at time $t$, and we want to calculate the endogenous outcomes of the model in $t+1$. Given the initial values of GDP $\left(Y_{n, t}\right)$, gross production in merchandised goods $\left(Y_{n, t}^{G}\right)$, labor hours $\left(l_{n, t}\right)$, trade shares of merchandised goods $\left(\pi_{n i, t}^{G}\right)$, expenditure on consumption goods $\left(X_{n, t}^{C}\right)$, and changes to capital $\left(\widehat{K}_{n, t+1}\right)$, and the paths of shocks $\widehat{\Psi}_{t+1}$, I recover the next period's endogenous outcomes. In other words, using $\widehat{\Psi}_{t+1}$, I can calculate the next period's GDP $\left(Y_{n, t+1}\right)$, gross production of merchandised goods $\left(Y_{n, t+1}^{G}\right)$, labor hours $\left(l_{n, t+1}\right)$, bilateral trade shares $\left(\pi_{n, t+1}^{G}\right)$, and consumption spending $\left(X_{n, t+1}^{C}\right)$, and changes to capital $\left(\widehat{K}_{n, t+2}\right)$.

Suppose that the path of capital $\widehat{K}_{n, t+1}$ and the entire paths of shocks $\Psi_{t+1}$ are given under perfect foresight equilibrium. Given the initial values of $Y_{n, t}, Y_{n, t}^{G}, l_{n, t}, X_{n, t}^{C}$, and $\pi_{n i, t}^{G}$, I obtain the next period's outcomes using the following conditions:

(i) Using TFP shocks to services sector $\widehat{z}_{n, t+1}^{S}$, changes to intermediate price index for services sector can be obtained using

$$
\widehat{p}_{n, t+1}^{S}=\frac{\left[\left(\widehat{w}_{n, t+1}\right)^{\alpha_{n}}\left(\widehat{r}_{n, t+1}\right)^{1-\alpha_{n}}\right]^{\beta_{n}^{S}}\left[\left(\widehat{p}_{n, t+1}^{S}\right)^{\gamma_{n}^{S}}\left(\widehat{q}_{n, t+1}^{G}\right)^{1-\gamma_{n}^{S}}\right]^{1-\beta_{n}^{S}}}{\widehat{z}_{n, t+1}^{S}}
$$

(ii) Using productivity shocks to tradable sector $\widehat{z}_{n, t+1}^{G}$, changes to price for merchandised goods is 


$$
\widehat{p}_{n, t+1}^{G}=\frac{\left[\left(\widehat{w}_{n, t+1}\right)^{\alpha_{n}}\left(\widehat{r}_{n, t+1}\right)^{1-\alpha_{n}}\right]^{\beta_{n}^{G}}\left[\left(\widehat{q}_{n, t+1}^{G}\right)^{\gamma_{n}^{G}}\left(\widehat{p}_{n, t+1}^{S}\right)^{1-\gamma_{n}^{G}}\right]^{1-\beta_{n}^{G}}}{\widehat{z}_{n, t+1}^{G}}
$$

(iii) Changes to the composite tradable goods price index is

$$
\widehat{q}_{n, t+1}^{G}=\left[\sum_{i=1}^{N} \pi_{n i, t+1}^{G}\left(\widehat{p}_{i, t}^{G} \widehat{d}_{n i, t+1}^{G}\right)^{\frac{\sigma}{\sigma-1}}\right]^{\frac{\sigma-1}{\sigma}}
$$

(iv) Using shocks to tradable goods sector $\widehat{\theta}_{n, t+1}$, changes to final goods price index is

$$
\widehat{q}_{n, t+1}=\left[\frac{X_{n, t}^{F, G}}{X_{n, t}^{F}} \widehat{\theta}_{n, t+1}\left(\widehat{q}_{n, t+1}^{G}\right)^{\frac{\mu}{\mu-1}}+\frac{X_{n, t}^{F, S}}{X_{n, t}^{F}}\left(\widehat{p}_{n, t+1}^{S}\right)^{\frac{\mu}{\mu-1}}\right]^{\frac{\mu-1}{\mu}}
$$

where $X_{n, t}^{F, G}$ and $X_{n, t}^{F, S}$ are the total expenditure of merchandised goods and services in producing final goods. The two expenditures sum up to $X_{n, t}^{F}$.

(v) Using bilateral trade frictions $\widehat{d}_{n i, t+1}^{G}$, changes to shares of tradable merchandised goods in country $n$ from country $i$ is

$$
\widehat{\pi}_{n i, t+1}^{G}=\left(\frac{\widehat{p}_{i, t+1}^{G} \widehat{d}_{n i, t+1}^{G}}{\widehat{q}_{n, t+1}^{G}}\right)^{\frac{\sigma}{\sigma-1}}
$$

(vi) Using aggregate demand shocks $\widehat{\phi}_{n, t+1}$, changes to expenditure in consumption spending is

$$
\widehat{X}_{n, t+1}^{C}=\widehat{q}_{n, t+1} \widehat{C}_{n, t+1}=\widehat{\phi}_{n, t+1}
$$

(vii) Using leisure shocks $\widehat{\xi}_{n, t+1}$, changes to leisure is

$$
\widehat{1-l_{n, t+1}}=\frac{\widehat{\phi}_{n, t+1} \widehat{\xi}_{n, t+1}}{\widehat{w}_{n, t+1} \widehat{N}_{n, t+1}}
$$

(viii) Using investment shocks $\widehat{\chi}_{n, t+1}$, changes to investment spending, $\widehat{X}_{n, t+1}^{I}$, satisfies the Euler equation 


$$
1=\rho \frac{\widehat{q}_{n, t+1}}{\widehat{\chi}_{n, t+1}}(1-\delta)+\rho \frac{r_{n, t+1} K_{n, t+1}}{X_{n, t}^{I}}\left(1-(1-\delta) \widehat{K}_{n, t+1}^{-1}\right)
$$

where the expression $r_{n, t+1} K_{n, t+1}$ comes from the market clearing condition for capital.

(ix) Using the capital market clearing condition, changes to rental rates and capital satisfy

$$
\widehat{r}_{n, t+1} \widehat{K}_{n, t+1} r_{n, t} K_{n, t}=\left(1-\alpha_{n}\right) Y_{n, t+1}
$$

(x) Using the labor market clearing condition, changes to wages and labor satisfy

$$
\widehat{w}_{n, t+1} \widehat{l}_{n, t+1} \widehat{N}_{n, t+1} w_{n, t} l_{n, t} N_{n, t}=\left(\alpha_{n}\right) Y_{n, t+1}
$$

(xi) And the market clearing conditions hold from the previous section.

Given the initial values of GDP $\left(Y_{n, t}\right)$, gross production in merchandised goods $\left(Y_{n, t}^{G}\right)$, labor hours $\left(l_{n, t}\right)$, trade shares of merchandised goods $\left(\pi_{n i, t}^{G}\right)$, expenditure on consumption goods $\left(X_{n, t}^{C}\right)$, and changes to capital $\left(\widehat{K}_{n, t+1}\right)$, and equipped with equations (i) - (xi), I can calculate the next period's GDP $\left(Y_{n, t+1}\right)$, gross production in merchandised goods and services $\left(Y_{n, t+1}^{j}\right.$ for $\left.j\{G, S\}\right)$, labor hours $\left(l_{n, t+1}\right)$, consumption spending $\left(X_{n, t+1}^{C}\right)$, imported trade shares $\left.\pi_{n i, t+1}\right)$, and subsequent capital stocks in changes $\left(\widehat{K}_{n, t+2}\right)$. I repeat this process for the next period. 


\section{E Numerical Algorithm}

In this section of the appendix, I write down the algorithm that solves for the social planner's problem. Expressing all the variables in changes is the key to this algorithm as I do not have to find everything in levels.

\section{E.1 Calculating the Counterfactual Equilibrium between 1992-1993}

We start with the economic outcomes in 1992: $Y_{n, 92}, Y_{n, 92}^{G}, l_{n, 92}, \pi_{n i, 92}, X_{n, 92}^{C}$, and $\widehat{K}_{n, 93}$. Even though a set of counterfactual shocks arrive between 1992 and 1993, changes to the capital, $\widehat{K}_{n, 93}$, had been decided by the social planner in the beginning of 1992. After the planner has allocated the endogenous outcomes in the beginning of 1992, the counterfactual bilateral trade shocks arrive

$$
\widehat{d}_{n i, 1993}=1 \quad \text { if } \quad n \neq i
$$

This means that the bilateral trade shocks remain constant (fixed) at 1992 levels. Meanwhile, all other country-specific shocks are left unchanged.

Between 1992 and 1993, the shocks were not anticipated by the social planner. Therefore, the Euler equation cannot hold as the capital that the planner allocated is is not efficiently allocated. Instead, the planner solves for the changes in investment spending:

$$
\widehat{X}_{n, 93}^{I}=\left(\frac{\widehat{K}_{n, 94}-(1-\delta)}{\widehat{K}_{n, 93}-(1-\delta)}\right) \frac{\widehat{q}_{n, 93} \widehat{K}_{n, 93}}{\widehat{\chi}_{n, 93}}
$$

and solve for the other equilibrium outcomes, while minimizing the market clearing conditions:

$$
\begin{gathered}
\widehat{w}_{n, t+1} \widehat{l}_{n, t+1} \widehat{N}_{n, t+1}=\widehat{Y}_{n, t+1} \\
\widehat{r}_{n, t+1} \widehat{K}_{n, t+1}=\widehat{Y}_{n, t+1}
\end{gathered}
$$

Then, I obtain $Y_{n, 93}, Y_{n, 93}^{G}, l_{n, 93}, \pi_{n i, 93}, X_{n, 93}^{C}$, and $\widehat{K}_{n, 94}$. Starting from 1994 , however, the counterfactual shocks are all known to the planner as she now fully realizes the altered paths of shocks. Therefore, the planner re-optimizes by taking the set of counterfactual shocks as given and optimally allocate all the outcomes for each country. ${ }^{40}$ All of the counterfactual exercises are done based on this philosophy.

\footnotetext{
${ }^{40}$ Starting from 1994, the Euler equation holds every period.
} 


\section{F Goodness of Fit}

\section{F.1 Non-Targeted Moments in the Model}

In the main calibration, I matched the endogenous outcomes of the structural model to seven data sources: GDP, gross production in merchandised goods, consumption expenditure of households and government, labor hours, producer and consumer price indices (PPI and CPI), and imports between countries, to back out seven sets of shocks. On the other hand, there are a number of un-targeted moments that were left to be solved in the equilibrium. In this section, I compare some of the un-targeted moments in the model to their data counterparts to check for the goodness of fit.

Wages. I compare the changes to wages, $\widehat{w}_{n, t}$, recovered from the model to the data for each country. I use average real annual wages, with constant 2011 prices to be consistent with the data. The correlation between wages from the model and from the data counterpart is about 0.2 . When I look at the G7 countries individually, wages for the United States capture the data quite well, as the correlation is 0.56. On the other hand, other countries range between 0 and 0.3. The main portion of the wages that the model cannot capture is the fall in real wages during the Greek Financial Crisis. Even though the model is not expected to match the un-targeted moments, the correlation for wages is positive.

\begin{tabular}{llllllll}
\hline Countries & CAN & DEU & FRA & GBR & ITA & JPN & USA \\
\hline Correlation & 0.2422 & -0.0436 & 0.0702 & 0.1300 & 0.05 & 0.3230 & 0.5596 \\
\hline
\end{tabular}

Table 16: Wages: Model vs. Data

Investment Spending. I compare the investment spending, $\widehat{X}_{n, t}^{I}$, with its data counterpart. I compare the correlations with the gross capital formation from the OECD STAN (WIOT), in 2011 US dollars.

\begin{tabular}{llllllll}
\hline Countries & CAN & DEU & FRA & GBR & ITA & JPN & USA \\
\hline Correlation & 0.62 & 0.2806 & 0.5091 & 0.6914 & 0.4261 & 0.3001 & 0.9439 \\
\hline
\end{tabular}

Table 17: Investment Spendings: Model vs. Data

Capital Stocks. I compare the changes to capital stocks in the model and from the data. The capital stocks are from the Penn World Table (PWT 9.1) in 2011 US dollars. I calculate the correlations between the time series of capital stocks that I backed out and the capital stocks from the data.

\begin{tabular}{llllllll}
\hline Countries & CAN & DEU & FRA & GBR & ITA & JPN & USA \\
\hline Correlation & 0.4103 & 0.4346 & 0.3711 & 0.2387 & 0.2334 & -0.4668 & 0.6430 \\
\hline
\end{tabular}

Table 18: Capital Stocks: Model vs. Data 


\section{G Robustness Checks}

What is crucial about the results in this paper is that the analyses depend on the model's time-invariant, initial parameters. In this section, I run several robustness checks with different initial parameters, especially the elasticity of substitution between home and foreign merchandise, and the elasticity of substitution between final merchandise and services.

\section{G.1 Elasticity Between Domestic and Foreign Goods}

In the main results section, I calibrate the model so that the trade elasticity matches the standard international real business cycle elasticity of 1.5. We know that trade elasticity estimates in the standard international macroeconomics literature is quite low compared to those in the standard trade literature. Since trade elasticity is one of the important time-invariant parameters of the model, I run robustness checks with the higher trade elasticity estimates from the trade literature.

Table 11-Table 13 in the appendix show the robustness results with different trade elasticities. I run the counterfactual analyses with trade elasticities of 3 and 5 . The results are strongly robust to different trade elasticities during the early-2000s. However, we do see that the impact of the trade-linkage shocks quantitatively decreases as trade elasticity becomes higher. During the post-recovery period of the Great Recession (2008-2014), when trade elasticity is 3, the trade-linkage shocks still plays the largest role in business cycle synchronization. However, when elasticity is equal to 5 , correlated TFP shocks to merchandise have the largest impact. The correlated TFP shocks capture the decline in the manufacturing sector, especially durable goods, in this period (2008-2014), which is in line with what happened recently in the recession.

\section{G.2 Elasticity Between Goods and Services}

I calibrate the model so that the elasticity of substitution between final merchandised goods and final services is 2, which is taken from Johnson (2014). This means that the non-tradable final goods and non-tradable final services are substitutable. For robustness, I use the elasticity of 0.5 , so that the final merchandised goods and final services are complements. Table 14 in the Appendix shows the results for

the sensitivity analysis when the elasticity $\frac{1}{\mu-1}$ is 0.5 . I still find that the trade-linkage shocks contribute to GDP correlations in the data after 2000. One of the differences with the main results of this paper is that in the 1990s, TFP shocks' dampening effects are much larger, and contributions of sectoral shocks to merchandised goods disappear during the post-recovery period. 